\title{
The Estimation of the Quenching Effects After Carburising Using an Empirical Way Based on Jominy Test Results
}

\author{
Mihai Ovidiu Cojocaru, Niculae Popescu and Leontin Drugă \\ "POLITEHNICA" University, Bucharest, \\ Romania
}

\section{Introduction}

The graphical and analytical solutions to solve the information transfer from the Jominy test samples to real parts are shown. The essay regarding the analytical solutions for the information transfer from the Jominy test samples to real parts includes detailed information and exemplifications concerning the essence and using the Maynier-Carsi and Eckstein methods in order to determine the quenching constituents proportions corresponding to the different carbon concentrations in carburized layers, respectively the hardness profiles of the carburized and quenched layers. In the final of the chapter, taking into account the steel chemical composition, the geometrical characteristics of the carburized product, the quenching media characteristics, the heat and time parameters of the carburising and the correlations between these values and the Jominy test result, an algorithm to develop a software for the estimation of the quenching effects after carburising, based on the information provided by Jominy test, is proposed.

\section{The particularities of quenching process after carburising}

The aim of the quenching process after carburizing is to transform the "austenite" with high and variable carbon content of the carburized layer in quenching "martensite", respectively the core austenite in non martensitic constituents (bainite, quenching troostite, and ferriteperlite mixture). This goal is achieved by transferring the parts from carburizing furnace into a cooling bath containing a liquid cooling (quenching) medium. The transfer can be directly made from the carburizing temperature (direct quenching), or after a previous precooling of parts from the carburizing temperature to a lower quenching temperature (direct quenching with pre-cooling). In both ways, the austenitic grain size is the same (depending on the chosen carburising temperature and time), but the thermal stresses are different, being higher in the case of direct quenching and lower in the case of direct quenching with pre-cooling, due to higher thermal gradient achieved in the first cooling variant. Consequently, the risks of deformation or cracking of the parts are lower in the pre-cooling quenching, this variant being most commonly used in the industrial practice.

On the other hand, the result of quenching is influenced by three factors: one internal, intrinsic hardenability of steel (determined by its chemical composition - carbon content, 
alloying elements type and percentage) and two external (technological) - thickness of the parts, expressed by an equivalent diameter $D_{\text {ech }}$ (the actual diameter in the case of cylindrical parts, or the diameter calculated using empirical relations for the parts with non cylindrical shapes) and cooling capacity of quenching media, expressed by relative cooling intensity - H (in rapport with a standard cooling media - still or low agitation industrial water at $20^{\circ} \mathrm{C}$ ). In Fig. 1 an empirical diagram of transformation of non cylindrical sections (prisms, plates) in circular sections with the equivalent diameter $\mathrm{D}_{\text {ech }}$ is shown; in Table 1, the indicative values of the relative cooling intensity of water and quenching oils - $\mathrm{H}$ are given depending on their degree of agitation related to the parts that will be quenched. If the parts have hexagonal section, it shall be considered that the cylindrical equivalent section has the $\mathrm{D}_{\text {ech }}$ equal to the "key open" of hexagon.

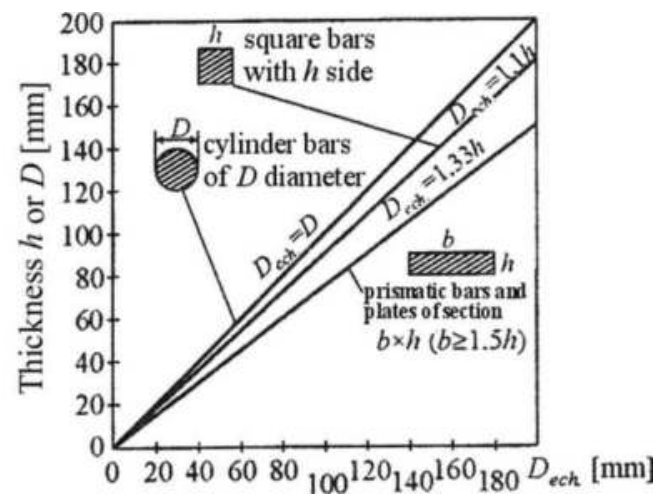

Fig. 1. Diagram for equalization of the square and prismatic sections with circular sections with diameter of $\mathrm{D}_{\text {ech. }}$

\begin{tabular}{|c|c|c|}
\hline Quenching media & $\begin{array}{c}\text { Relative agitating degree parts/cooling } \\
\text { medium }\end{array}$ & $\begin{array}{c}\text { Relative cooling } \\
\text { intensity, } \mathrm{H}\end{array}$ \\
\hline \multirow{4}{*}{$\begin{array}{c}\text { Mineral oils, } \\
\text { at } \mathrm{T}=50 \sim 80^{\circ} \mathrm{C}\end{array}$} & without agitation & 0.20 \\
\cline { 2 - 3 } & low & 0.35 \\
\cline { 2 - 3 } & average & 0.45 \\
\cline { 2 - 3 } & good & 0.60 \\
\hline \multirow{4}{*}{ Water at approx. $20^{\circ} \mathrm{C}$} & strong & 0.70 \\
\cline { 2 - 3 } & without agitation & 0.9 \\
\cline { 2 - 3 } & low & 1.0 \\
\cline { 2 - 3 } & average & 1.2 \\
\hline \multirow{3}{*}{$\mathrm{NaCl}$ aqueous solution, } & good & 1.4 \\
\cline { 2 - 3 } $\mathrm{T}=20^{\circ} \mathrm{C}$ & strong & 1.6 \\
\cline { 2 - 3 } & low & 2.0 \\
\cline { 2 - 3 } & average & 3.0 \\
\cline { 2 - 3 } & good & 5.0 \\
\hline
\end{tabular}

Table 1. Correlation between nature, degree of agitation and relative cooling intensity of common cooling media. 
Lately, in the industrial practice, the so-called synthetic quenching media with cooling capacity that can be adjusted in wide limits have also been used, from the values specific to mineral oils to those specific to water, by varying the chemical composition, temperature and degree of agitation.

The degree of agitation of quenching media can be adjusted by the power and / or frequency of propellers or pumps type agitators, mounted in the quenching bath integrated in the carburizing installation (batch furnaces).

The external factors $\left(\mathrm{D}_{\text {ech }}, \mathrm{H}\right)$ determine cooling law of the parts, respectively cooling curves of the points from surface or internal section of the parts; the internal factor (steel hardenability) determines quenching result, expressed by structure obtained from transformation of continuously cooled austenite from austenitizing temperature to final cooling temperature of assembly - parts-quenching medium.

To foresee or verify the structural result of quenching, the overlapping of the real cooling curves (determined by external factors $\mathrm{D}_{\text {ech }}$ and $\mathrm{H}$ ) over the cooling transformation diagram of austenite of chosen steel at continuous cooling can be made, which is a graphical expression of intrinsic hardenability of steel.

The diagram of austenite transformation at continuous cooling allows steel to achieve both a quantitative assessment of the quenching structure, the estimation sizes being the proportions of martensitic and non martensitic constituents and to estimate the hardness of quenching structure.

\section{Use of Jominy frontal quenching sample for estimation of quenching process results}

The estimation of the steel quenching effects represents an extremely complex stage due to large number of variables that influence this operation, respectively: steel chemical composition, austenitizing temperature in view of quenching, the parts thickness and the quenching severity of the quenching media. The problem can be solved in an empirical way using the frontal quenched test sample, designed and standardized by W. E. Jominy and A. L. Boegehold and named Jominy sample (Jominy test). The simple geometry of sample and the way of performing the Jominy test covers a large range of cooling laws, their developing in terms of coordinates $\mathrm{T}$ - $\mathrm{t}$ being dependent on the distance from the front quenched part to the end of the Jominy sample. Using these curves a series of kinetic parameters of the cooling process can be obtained: cooling time and temporary (instantaneous) cooling speeds or cooling speeds appropriate for different thermal intervals. From its discovery (1938) until present, the Jominy test has been the object of numerous determinations and interpretations, evidenced especially by means of drawing of the cooling curves, of the points placed at certain distances from the frontal quenched end. The European norm, ISO/TC17/SC7N334E, Annex B1, specify the aspect of the Jominy samples cooling curves in the surface points placed at the distances $\mathrm{dj}=2.5 ; 5 ; 10 ; 15 ; 25 ; 50$ and $80 \mathrm{~mm}$ from the frontal quenched end (Fig.2 [1]). This representation has the advantage that can be applied to each steel and for each austenitizing temperature $\mathrm{T}_{\mathrm{A}}$ in terms of quenching, in the common limits $\mathrm{T}_{\mathrm{A}}=830 \sim 900^{\circ} \mathrm{C}$, because has on the ordinate axis the relative temperature $\theta=T / T_{A}$, respectively the ratio between the current temperature $T$ (in a point placed at the 


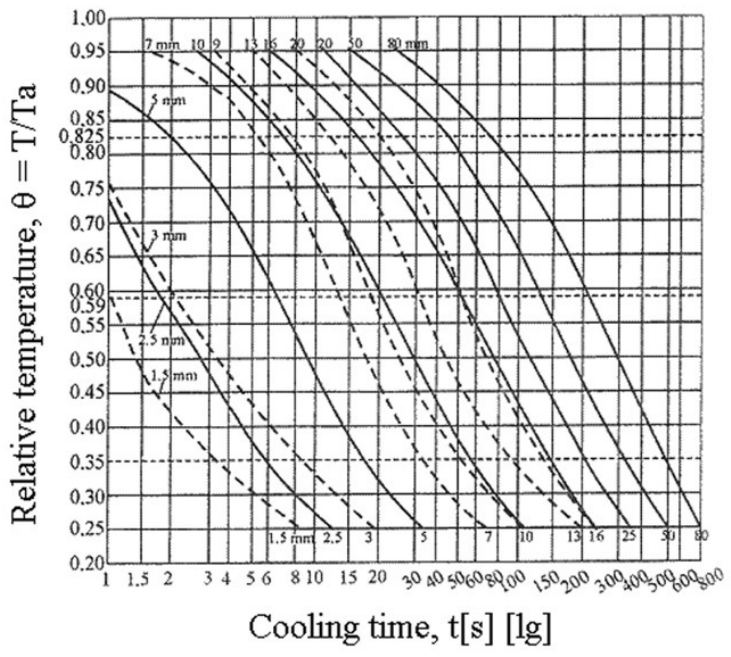

Fig. 2. Cooling curves of some points placed at different distances from the frontal quenched end of Jominy sample: continuous lines according to ISO/TC17/SC7N334E

Standards; dashed lines - - - according to G. Murry[1].

distance $d \mathrm{j}$, after the time $\mathrm{t}$ ) and the austenitizing temperature $\mathrm{T}_{\mathrm{A}}$. In the diagram presented in Fig. 2 the cooling curves for $\mathrm{dj}=1.5 ; 3 ; 7$ and $13 \mathrm{~mm}$ taken from the work [1] and adapted to ordinate $\theta=\mathrm{T} / \mathrm{T}_{\mathrm{A}}=\mathrm{T} / 850$ are also shown. The most used kinetics parameters from the data given by the cooling curves, specific to Jominy sample and that can indicate, in a large measure, the structural result of the quenching process after carburizing are as follows:

1. the time set for passing through the temperature of $700^{\circ} \mathrm{C}\left(\mathrm{t}_{700} \equiv \mathrm{t}_{0.825 \mathrm{TA}}\right)$ and the corresponding actual cooling speed, $v_{0.825 T_{A}}=\frac{T_{A}-0.825 T_{A}}{t_{0.825 T_{A}}}=\frac{0.175 T_{A}}{t_{0.825 T_{A}}}$ for each austenitizing temperature that provides the avoiding of the transformation of the under cooled austenite in perlitical stage constituents;

2. the time set for passing through the temperature of $500^{\circ} \mathrm{C}\left(\mathrm{t}_{500} \equiv \mathrm{t}_{0.59 \mathrm{TA}}\right)$ and the corresponding actual cooling speed, $v_{500}=\frac{300}{t_{500}}$ for $\mathrm{T}_{\mathrm{A}}=850^{\circ} \mathrm{C}$, respectively $v_{0.59 T_{A}}=\frac{T_{A}-0.59 T_{A}}{t_{0.59 T_{A}}}=\frac{0.41 T_{A}}{t_{0.59 T_{A}}}$, that provides the avoiding of the transformation of the under cooled austenite in bainitic stage constituents; the thermal interval is also noted as $\Delta_{t_{0.59 T_{A}}^{T_{A}}}$ or with $\mathrm{t}_{\mathrm{A} / 5}$

3. the time set for passing through the temperature of $300^{\circ} \mathrm{C}\left(\mathrm{t}_{300}=\mathrm{t}_{0.35 \mathrm{TA}}\right)$ and the corresponding actual cooling speed, $v_{300}=\frac{850-300}{t_{300}}=\frac{550}{t_{300}}$ for $\mathrm{T}_{\mathrm{A}}=850^{\circ} \mathrm{C} \quad$ and $v_{0.35 T_{A}}=\frac{T_{A}-0.35 T_{A}}{t_{0.35 T_{A}}}=\frac{0.65 T_{A}}{t_{0.35 T_{A}}}$ for each $\mathrm{T}_{\mathrm{A}}$ determines the passing of the under cooled austenite through the $\mathrm{Ms} \leq 300^{\circ} \mathrm{C}$ and its transformation in quenching martensite; 
4. the time interval $\Delta t_{300}^{850}=t_{300}-t_{850}$ for $\mathrm{T}_{\mathrm{A}}=850^{\circ} \mathrm{C}$, respectively $\Delta t_{0.35 T_{A}}^{0.825 T_{A}}$, for each $\mathrm{T}_{\mathrm{A}}$ and the average cooling speed of austenite in these temperature intervals , $\bar{v}_{300}^{850}=\frac{850-300}{\Delta t_{300}^{850}}=\frac{550}{\Delta t_{300}^{850}}$, for $\mathrm{T}_{\mathrm{A}}=850^{\circ} \mathrm{C}$, respectively $\bar{v}_{0.35 T_{A}}^{0.825 T_{A}}=\frac{0.825 T_{A}-0.35 T_{A}}{\Delta t_{0.35 T_{A}}^{0.825 T_{A}}}$ for each $\mathrm{T}_{\mathrm{A}}$.

These parameters provide the cooling of the under cooled austenite in the range of $\mathrm{M}_{\mathrm{S}}-\mathrm{M}_{\mathrm{f}}$ and its transformation in quenching martensite. The above mentioned kinetic parameters are determined for each cooling curve, corresponding to a certain distance $d_{J}[\mathrm{~mm}]$ from the frontal quenched end of the Jominy test sample (Fig. 3).

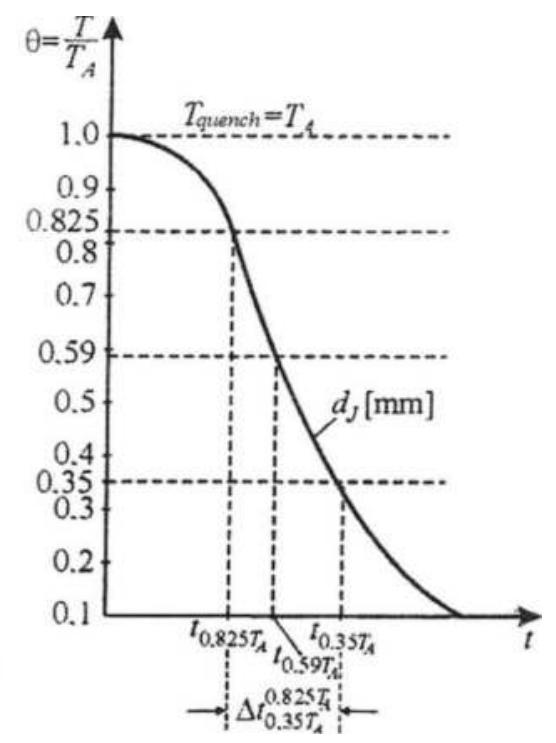

Fig. 3. The graphical determination of the temporal kinetic parameters related to the cooling curve of the points from the surface of the Jominy test sample, placed at the distance $d_{J}$ $[\mathrm{mm}]$ from the frontal quenched end. Obs. Example for graphical determination of the temporal kinetic parameters $\mathrm{t}_{0,825 \mathrm{TA}} ; t_{0.59 T_{A}}=\Delta_{0.59 T_{A}}^{T_{A}}=t_{A / 5} ; \mathrm{t}_{0.35 \mathrm{TA}}$ and $\Delta t_{0.35 T_{A}}^{0.825 T_{A}}$, from the cooling curve corresponding to the distance $d_{J}[\mathrm{~mm}]$ from the frontal quenched end.

Analyzing the cooling curves from Fig. 2, a difference between those taken from the ISO standard and those from G. Murry work, is observed. To clarify these discrepancies and to adopt an unique and argued assessment of the way of setting out of the cooling curves in the case of Jominy samples, we can start to analyze the modality in which the heat transfers from Jominy sample to the ambient, during cooling of the sample from the austenitizing temperature $\mathrm{T}_{\mathrm{A}}$ to the ambient temperature $\mathrm{T}_{\mathrm{amb}}$ took place.

In principle, the heat flow in a point $\mathrm{P}$ of the Jominy sample, placed at distance $\mathrm{x}$ from the frontal quenched end and at the distance $r$ from the axis of the sample, at time $t$ after the start of cooling is given by the differential equation: 


$$
Q_{P(t)}=Q_{(r, x, t)}=\frac{\lambda}{r} \frac{\partial}{\partial r}\left(r \frac{\partial T_{(x, r, t)}}{\partial r}\right)
$$

this can be solved in the following univocity conditions:

a. initial condition: $\mathrm{T}_{(\mathrm{x}, 0)}=\mathrm{T}_{\mathrm{A}}$;

b. boundary conditions of first order: $\quad \mathrm{T}_{(0, t)}=\mathrm{T}_{\text {water jet }}$ (on the water cooled surface)

$\mathrm{T}_{(\mathrm{x}, \mathrm{t})}=\mathrm{T}_{\mathrm{amb}}$ (along the cylinder generator)

c. boundary conditions of second order defined by the specific heat flux through the frontal cooled surface and through the external cylindrical surface cooled in air, which are proportional with the negative temperature gradients:

$$
W_{F}=-\lambda \frac{\partial T_{(0, t)}}{\partial x} \text {, respectively } W_{c i l}=-\lambda \frac{\partial T_{(x, t)}}{\partial x}
$$

The heat loss during sample cooling takes place by means of three mechanisms:

- conduction - at the contact interface between cooling water and direct cooled surface, the heat loss value being a function of time:

$$
W(t)=q(t)
$$

- convection - of the ambient air, the heat loss value being a function of the $T_{(x, t)}-T_{a m b}$ difference

$$
\mathrm{W}(\mathrm{t})=\alpha\left[\left(\mathrm{T}_{(\mathrm{x}, \mathrm{t})}-\mathrm{T}_{\mathrm{amb}}\right)\right]
$$

where $\alpha$ is the convection heat transfer coefficient:

- $\quad$ radiation - from the cylindrical surface:

$$
W(t)=\beta\left[\left(T_{(x, t)}^{4}-T_{a m b}^{4}\right)\right]
$$

where $\beta$ is the radiation constant, $\beta=\varepsilon \sigma$;

$\varepsilon$ is the emissivity coefficient of the sample surface;

$$
\sigma=5.67 .10^{-8}\left[\frac{\mathrm{J}}{\mathrm{m}^{2} \mathrm{sK}^{4}}\right]
$$

The solving of the differential equation (1) lead to a solution representing the general form of the cooling curves equations of points placed at the distance $x$ from the frontal quenched end:

$$
T_{(x, t)}=T_{a m b}+\left(T_{A}-T_{a m b}\right) \exp \left(-\frac{c}{x} t\right)
$$

where the parameter $\mathrm{c}$ has speed dimensions $(\mathrm{m} / \mathrm{s})$, and the rapport $\mathrm{c} / \mathrm{x}$ is a constant on which the temporary (instantaneous) cooling speed has a linear dependency:

$$
v=\frac{\partial T}{\partial t}=\left(T_{a m b}-T\right) \frac{c}{x}
$$


To simplify the analysis, without introducing further errors, can be admitted that $\mathrm{T}_{\mathrm{amb}} \sim 0$ and noting $T_{(x, t)}=T_{S}$ (the current surface temperature) and $T_{S} / T_{A}=\theta$ (the relative surface temperature), the final solution can be written as:

$$
\theta=e^{-\frac{c}{x} t}
$$

The solution (6) makes the direct connection between the relative temperature $\theta$ and time $t$, values that represent the coordinates in which are drawn the cooling curves of the points (planes) placed at the distance $x$ from the frontal quench end of the Jominy sample.

In the work [2] the using of the relation (4) is exemplified in the case of Jominy samples austenitized at $\mathrm{T}_{\mathrm{A}}=1050^{\circ} \mathrm{C}$, for which the cooling curves of the points placed at the distances $x=1,10,20$ and $40 \mathrm{~mm}$ from the frontal quench end (Fig.4) were drawn and on which the ordinate referring to the relative temperature $\theta=\mathrm{T} / 1050$ and also the ISO and Murry cooling curves for distances $x=1.5 \mathrm{~mm}$ (Murry), 9mm (Murry), $10 \mathrm{~mm}$ (Murry), $20 \mathrm{~mm}$ (ISO and Murry) and $40 \mathrm{~mm}$ (Murry) were also drawn.

Using data taken from continuous curves presented in Fig.4 and replacing the notation $x$ which represents the distance from the frontal quenched end of Jominy sample with $E$, the value of parameter $c$ (from eq. 6 ) has found as $c=0.28$, so that eq.(6) of cooling curves will get a particular form (7) and the inverse function, $\mathrm{t}=\mathrm{f}(\theta)$ will have the expression (eq.8)

$$
\begin{gathered}
\theta=\mathrm{e}^{-\frac{0.28}{\mathrm{E}} \mathrm{t}} \\
t=-8.244 E \lg \theta
\end{gathered}
$$

On the other hand, from Fig. 4 it can be seen that between the aspect of the actual cooling curves experimentally determined by Murry and ISO and that obtained by calculation, using the relations (7) and (8), there are differences which are substantially and simultaneously amplifying with the decreasing of the relative temperature $\theta$. In conclusion, we can say that the theoretical analysis presented above is incomplete in that it fails to consider some effects of interaction between the types of heat loss during cooling of the Jominy samples.

Taking into account the higher matching of the Murry curves to theoretical curves, were mathematically processed the data provided by Murry curves and was noted that these are best described also by an exponential function, having the general form $t=a^{b}$, and the particular form as:

$$
t=a E^{1.41}
$$

where the parameter a depends on $\theta$ also by means of an exponential relation:

$$
a=0,2 \theta^{-2.4}
$$

In conclusion, the relations describing the dependencies $t=f(\theta, E)$ - eq.(8) and $\theta=f(t, E)$ eq. (7), will have the following particularly forms: 


$$
\begin{gathered}
t_{(E, \theta)}=0.2 \theta^{-2.4} E^{1.41} \\
\theta_{(E, t)}=0.51 E^{0.588} t^{-0.416}
\end{gathered}
$$

Once the Jominy sample kinetic parameters are known for a sample made from a certain charge of steel, they can be attributed to a specific part (with an equivalent diameter, $\mathrm{D}_{\text {ech }}$ known) made from the same charge of steel, taking into account that both the part and also the Jominy test sample to be processed in the same technological conditions (same austenitizing temperature $\mathrm{T}_{\mathrm{A}}$ and time $\mathrm{t}_{\mathrm{A}}$ ) and same quenching media (with the same relative cooling intensity, $\mathrm{H}$ ). This condition will be accomplished in the case where the Jominy sample is "embedded" in the heat treatment charge, composed of identical parts and follows the same processing sequence, in the same heating and cooling equipment. The correlation between the Jominy test sample and real part with the equivalent diameter of $\mathrm{D}_{\text {ech }}$ is usually graphically provided: a first chart was built by Jatczak [3] (for parts with equivalent discrete diameters of $12.5 \mathrm{~mm}, 19 \mathrm{~mm}, 25 \mathrm{~mm}, 38 \mathrm{~mm}, 50 \mathrm{~mm}$ and $100 \mathrm{~mm}$ ).

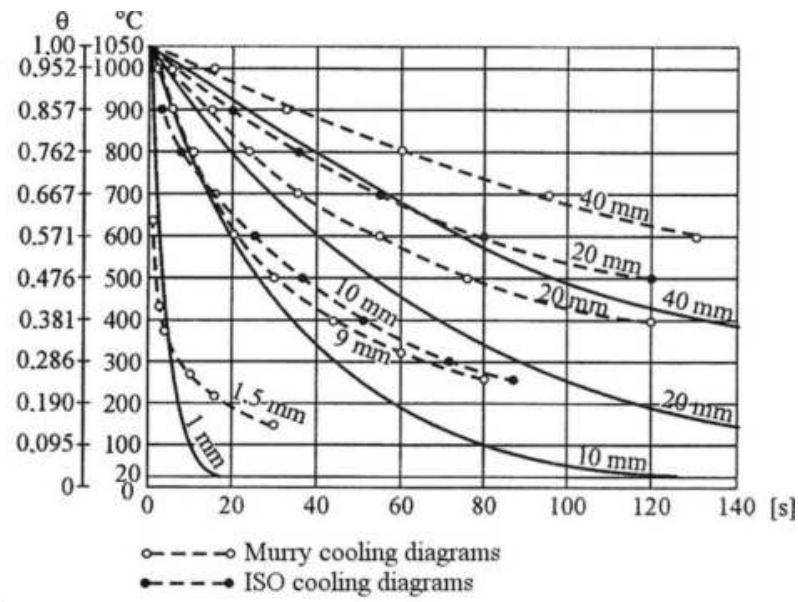

Fig. 4. The cooling curves drawn by means of relation (6), at distances $x=1,10,20$ and $40 \mathrm{~mm}$ after the cooling from $\mathrm{T}_{\mathrm{A}}=1050^{\circ} \mathrm{C}$ of Jominy samples (continuous lines curves) and the cooling curves drawn according to ISO and Murry (dashed curves).

From this diagram in Fig. 5 (in view of illustrating of application way) the graphic for the part with $\mathrm{D}_{\mathrm{ech}}=38 \mathrm{~mm}$ was displayed.

Jatczak diagram provides a graphical solution for the function $\mathrm{dj}=\mathrm{f}$ (Dech, $\mathrm{H}, \mathrm{r}), 0 \leq \mathrm{r} \leq$ where $\mathrm{R}$ is the coordinate position of the point on the part cylindrical section, that has the same cooling law (curve) with that of points situated in the plane placed at the distance dj from the frontal quenched end of the Jominy sample.

For parts subject to carburizing, the correlation diagram - cylindrical part - Jominy sample will become the curve from the Jatczak diagram, referring to part surface $S$ (as the layer thickness $\delta$ is very small compared to the equivalent radius of the part). In this case, the correlation function has the form $d j=f(D, H)$ or $D=f(d j, H)$, where $D$ is the diameter of 


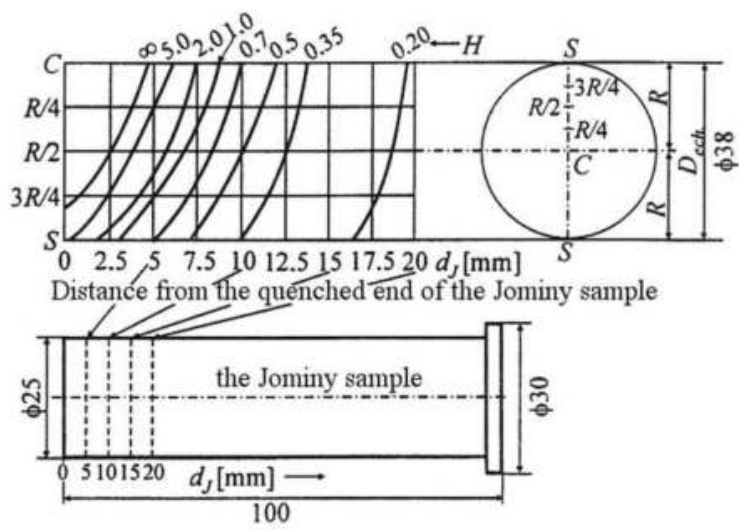

Fig. 5. Jatczak diagram of the sample (part) with $D_{\text {ech }}=38 \mathrm{~mm}$ and the correlation between points in section of part and points of the generator of Jominy sample placed at the distance dj from the frontal quenched end, after cooling in quenching media with different intensities of cooling., $\mathrm{H}$.

cylindrical part with length $L \geq 3 \mathrm{D}$ (or equivalent diameter of the parts with other forms of the section) and $\mathrm{dj}$ is the distance from the frontal quenched end of Jominy sample.

In Fig.6,the correlation diagram- Jominy sample - superficial layer of cylindrical parts drawn by U.Wyss [4] based on the method of Grossmann and numerous literature data is reproduced.

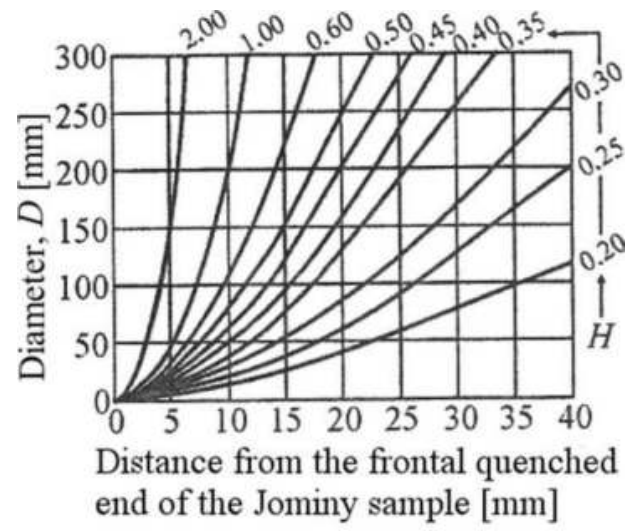

Fig. 6. The correlation curves for comparable cooling conditions in the Jominy sample and in the superficial layer of cylindrical parts at different values of cooling intensity of cooling media.

Replacing dj with notation $\mathrm{E}$ (the equivalent distance from the frontal quenched end of the Jominy sample) and statistically processing the data from Fig. 6, U. Wyss found the analytical relations for the inverse functions $E=f(D, H)$ and $D=f(E, H)$, as it follows : 
- $\quad$ For a cooling intensity of $\mathrm{H}=0.25$, corresponding to low agitated oil:

$$
D_{0.25}=E^{(1.27+0.0042 E)} E_{0.25}=D^{(0.755-0.0003 D)}
$$

- $\quad$ For a cooling intensity of $\mathrm{H}=0.35$, corresponding to average agitated oil:

$$
D_{0.35}=E^{(1.52+0.0028 E)} E_{0.35}=D^{(0.649-0.0001 D)}
$$

- $\quad$ For a cooling intensity of $\mathrm{H}=0.45$, corresponding to intensive agitated oil:

$$
D_{0.45}=E^{1.755} \quad E_{0.45}=D^{0.57}
$$

- $\quad$ For a cooling intensity of $\mathrm{H}=0.60$, corresponding to strong agitated oil:

$$
D_{0.60}=E^{2} \quad E_{0.60}=D^{0.50}
$$

- $\quad$ For a cooling intensity of $\mathrm{H}=1.00$, corresponding to low agitated water:

$$
D_{1.00}=E^{(2+0.03 E)} \quad E_{1.00}=D^{(0.47-0.00015 D)}
$$

The values of cooling intensity, $\mathrm{H}$, shown above, are suitable for quenching oil used at normal temperatures $\left(50 \sim 80^{\circ} \mathrm{C}\right.$ ) and with different degrees of agitation (of oil and/or parts) in a relatively wide range, starting from absence of agitation $(\mathrm{H}=0.25)$ to strong agitation $(\mathrm{H}=0.6)$, or a shower or pressure jet oil $(\mathrm{H}=1.00)$, this last situation being equivalent for low agitated cooling water at $20^{\circ} \mathrm{C}$, .

With these observations, the graphical relation between the carburized layer of part with diameter D and points from the Jominy sample, carburized in the same conditions, in accordance with the scheme shown in Fig.7 is achieved, where both the superficial layer of part and also the Jominy sample are represented at very high magnification in rapport with actual size (the dimension of the carburized layer $\delta \sim 0.5 \sim 2 \mathrm{~mm}$ and the equivalent distance in the Jominy sample $\mathrm{E} \sim 2 \sim 20 \mathrm{~mm}$ ).

\section{The graphical solving of correlation between real parts - Jominy sample}

From the graphical representation shown in the Fig. 7 results that the $A^{\prime}, B^{\prime}$ and $C^{\prime}$ points of the carburized layer of the Jominy test sample, equivalent to $A, B$ and $C$ points of the part carburized layer, are located on the intersections of the horizontal plane placed at the $\mathrm{E}$ distance from the frontal cooling plane of the Jominy test piece with the vertical planes placed at the $\mathrm{O}, \delta_{\text {ef }}$ and $\delta_{\text {tot }}$ from the Jominy test sample generator, characterized through the $\mathrm{C}_{\mathrm{s}}, \mathrm{C}_{\mathrm{ef}}$ and $\mathrm{C}_{\mathrm{m}}$ constant carbon contents.

Based on the above considerations, a graphical solution of the issue regarding the correlation between the Jominy test sample and a part with $\mathrm{D}$ diameter, both carburized in identical conditions (same carbon profile and same hardness profile in the carburized layer) has developed by U. Wyss. Using of Wyss graphics solution requires the knowledge of the equivalent diameter of the part (D), the cooling intensity of quenching media $(\mathrm{H})$, the carbon profile of carburized layer and the hardenability curves, respectively the hardness $=\mathrm{f}(\% \mathrm{C})$ curves at various depths $0 \leq \delta \leq \delta_{\text {tot }}$ in the case hardened layer of the Jominy test sample. 


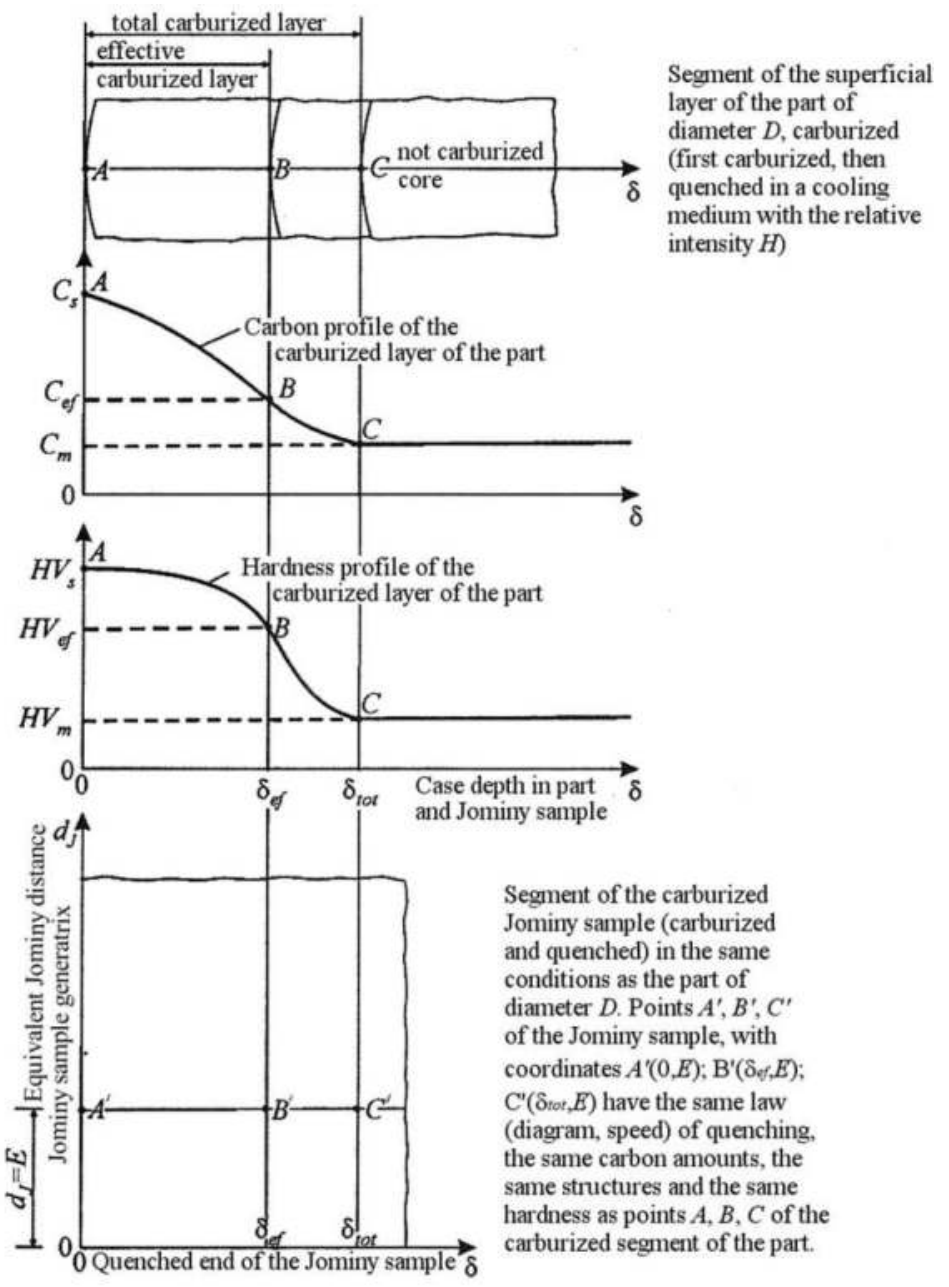

Fig. 7. The correlation scheme between part with equivalent diameter D and the Jominy sample, carburized in identical conditions.

The scheme of Wyss's graphical solution is represented in detail in Fig.8 for certain parts with the equivalent diameter $\mathrm{D}=35 \mathrm{~mm}$, made of case hardened steel with composition $0.16 \% \mathrm{C}, 1 \% \mathrm{Mn}$ and $1 \% \mathrm{Cr}$ that were carburized at $\mathrm{C}_{\mathrm{s}}=0.8 \%$ and quenched in hot oil with average agitation (cooling intensity of $\mathrm{H}=0.35$ ).

The information sources used by Wyss in developing of the scheme shown in Fig. 8 were the following:

- $\quad$ the $D=f(d j)$ dependence for $H=0.35$, has been taken from Fig. 6;

- the carbon profile curve has been experimentally plotting by means of sequential corrections of the case hardened layer of a part with dimensions of $\Phi 35 \times 105 \mathrm{~mm}$; 


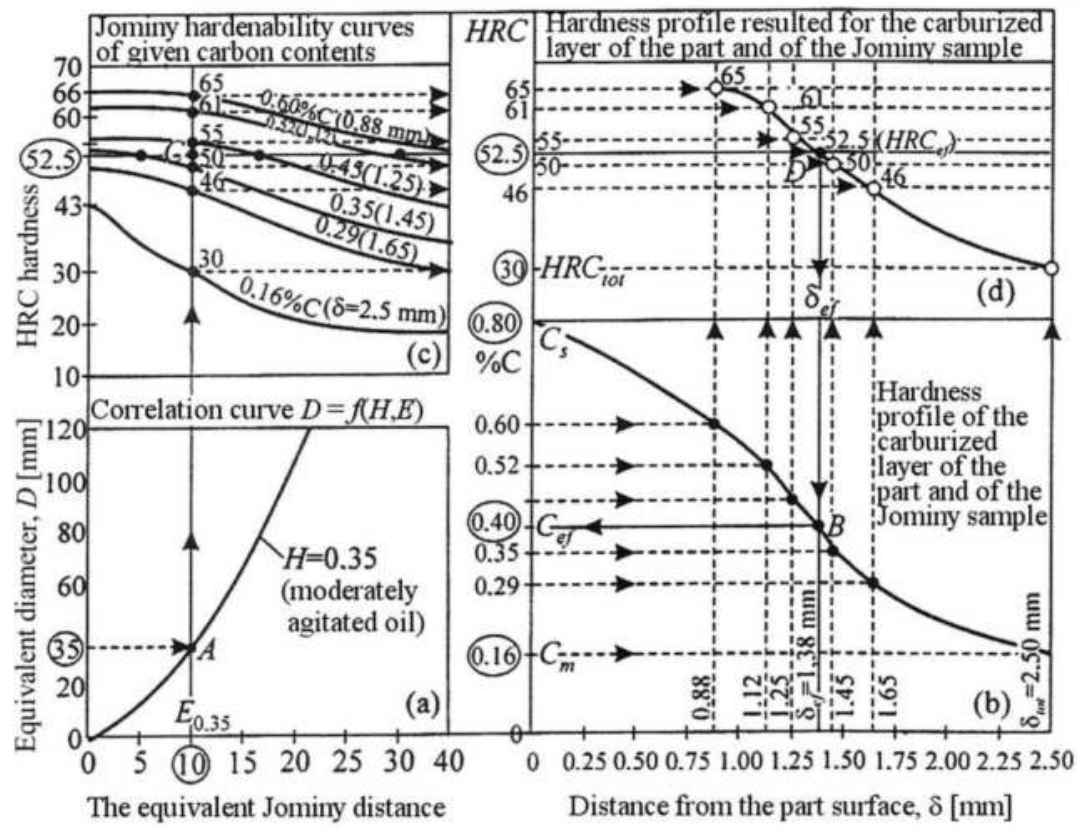

Fig. 8. Deduction of the hardness profile in the carburizing layer for parts(d) and for the Jominy test sample from Jominy hardenability curves (c) for a given carbon profile of carburizing layer (b), after carburising at $\mathrm{C}_{\mathrm{s}}=0.8 \% \mathrm{C}$ of parts made of a case hardening steel with composition $(0.16 \% \mathrm{C}, 1 \% \mathrm{Mn}, 1 \% \mathrm{Cr})$ and diameter $\mathrm{D}=35 \mathrm{~mm}$ and subsequent quenching in oil with cooling intensity $\mathrm{H}=0.35$ (according to Wyss [4]).

- the hardenability curves has been experimentally plotting by means of measuring of the HRC hardness on planes parallel with the Jominy test piece generator, corrected at the depths of the case hardened layer at which the carbon content is that mentioned on curve $(0.60 \% \mathrm{C} ; 0.52 \% \mathrm{C} ; 0.45 \% \mathrm{C} ; 0.35 \% \mathrm{C} ; 0.29 \% \mathrm{C}$ and $0.16 \% \mathrm{C})$.

The algorithm of using of the graphical solution is shown by arrows in Fig. 8 and involves the following steps:

- determination of the equivalent Jominy distance $E=f(D, H)$ - in chart (a) for $D=35 \mathrm{~mm}$ and $\mathrm{H}=0.35$ (the example in discussion), its value is $\mathrm{E}=10 \mathrm{~mm}$;

- by means of vertical $\mathrm{E}=10 \mathrm{~mm}$ (from the chart a) extended in the diagram (c) at its intersection with the hardenability curves, drawn for different concentrations of carbon in the case hardened layer of Jominy test sample, the appropriate hardness will be determined;

- from the intersection points of vertical line $\mathrm{E}=10 \mathrm{~mm}$ with the hardenability curves determined for different carbon concentrations in the case hardened layer of Jominy test sample are drawn horizontal lines which are extending in the space of the diagram shown in chart (d), so as to intersect the hardness profile curves for the case hardened layer (in the part and in the Jominy test sample); 
- $\quad$ in the diagram (b) the horizontals lines corresponding to the hardenability curves from the diagram(c) will be plotted and the points of intersection with the carbon profile curve will be determined; from these points, vertical lines extending in the space of the diagram (d) are drawn and cross the horizontals plotted in an earlier stage (from the intersection points of the vertical $\mathrm{E}=10 \mathrm{~mm}$ (diagram (a)) with the hardenability curves drawn for different carbon concentrations in the case hardened layer (diagram (c)); the intersection points belong to the hardness profile curve available for the existing space diagram (d). The point $\mathrm{D}$ in the diagram (d) in which the hardness profile curve crosses the horizontal corresponding to $\mathrm{HRC}_{\mathrm{ef}}$ hardness has the abscise corresponding to the effective depth $\delta_{\text {ef }}$ (in the example discussed, for $\mathrm{HRC}_{\mathrm{ef}}=52.5$ results $\delta_{\mathrm{ef}}=1.38 \mathrm{~mm}$ );

- from the crossing point $\mathrm{D}$, the vertical line which will meet the carbon profile curve at point $\mathrm{B}$ of which horizontal corresponds to the actual carbon content, $\mathrm{C}_{\mathrm{ef}}$ (for example the analysis made for $\delta \mathrm{ef}=1.38 \mathrm{~mm}$ results $\mathrm{C}_{\mathrm{ef}}=0.4 \% \mathrm{C}$ ).

\section{Essay regarding the analytical solving of the real parts-Jominy sample correlation}

The above graphical solution can be transformed into an analytical solution if the equations of the following curves are available:

a. $E=f(D, H)$ curve;

b. $\quad C=f(\delta)$ carbon profile curve;

c. Jominy hardenability curve, $\operatorname{HRC}=\mathrm{f}(\mathrm{C}, \mathrm{d})$

a. For the equation (a) it can be started from the mathematical processing of the Wyss particular relations no (13) (17) in order to their generalization. The performed attempts lead to two different types of generalized relations, applicable with satisfactory accuracy on different values ranges for the $\mathrm{H}, \mathrm{D}$ and $\mathrm{E}$ variables:

- $\quad$ for $0.25 \leq \mathrm{H} \leq 0.60,3 \leq \mathrm{E} \leq 18(\mathrm{~mm})$ and $4 \leq \mathrm{D} \leq 50(\mathrm{~mm})$ :

$$
\begin{aligned}
& \mathrm{D}=\exp \left(1.5 \mathrm{E}^{0.625}-\frac{0.16+0.08 \mathrm{E}}{\mathrm{H}}\right) \\
& E=D^{(0.755-0.0003 D)}-D \frac{H-0.25}{3 H-0.25}
\end{aligned}
$$

- $\quad$ for $0.6 \leq \mathrm{H} \leq 1,00 ; 2 \leq \mathrm{E} \leq 12(\mathrm{~mm})$ and $10 \leq \mathrm{D} \leq 100(\mathrm{~mm})$ :

$$
\begin{gathered}
D=E^{[2+0.075 E(H-0,6)]} \\
E=D^{[0,545-0,075 H-0,000375 D(H-0,6)]}
\end{gathered}
$$

The parts that will be case hardened by instillation and pyrolysis of organic liquids are usually thin pieces with $\mathrm{D}_{\mathrm{ech}} \leq 50 \mathrm{~mm}$, which are cooled in mineral oil with cooling intensity of $\mathrm{H} \sim 0.25 \sim 0.60$. To this category of products it can be applied the above mentioned relations no. (18-19) thus achieving results very close to those achieved using Wyss relations (Fig.9). 


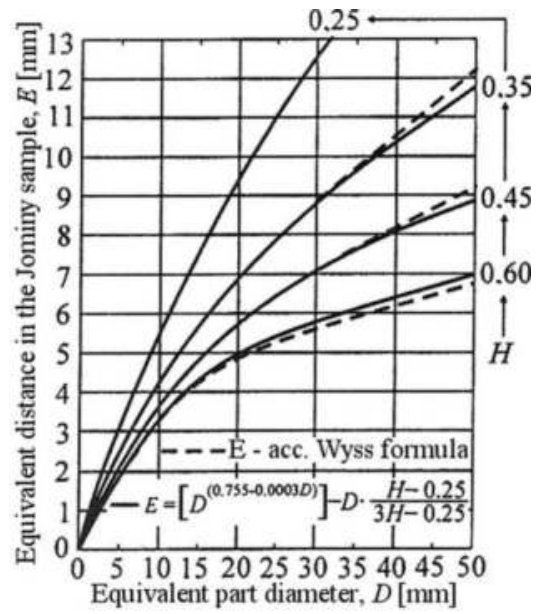

Fig. 9. Comparison between the effects of using of the Wyss particular relations and the relation no.(19) [5].

b. For the equation of the carbon profile curve (b), can be used the expression of criterial solution of the diffusion equation obtained through solving in the boundary conditions of III order - ec. 23, written under the form:

$$
\mathrm{C}_{\delta}=\mathrm{C}_{\mathrm{m}}+\theta\left(\mathrm{C}_{\mathrm{s}}-\mathrm{C}_{\mathrm{m}}\right)
$$

where $C_{\delta}$ represents the carbon content measured at the $\delta$ depth in rapport with the surface at the case hardening end; $\mathrm{C}_{\mathrm{m}}$ represents the carbon content of the non - case hardened core and $\mathrm{C}_{\mathrm{s}}$ is the surface carbon content at the end of case hardening.

$$
\theta=\frac{C_{\delta}-C_{m}}{C_{S}-C_{m}}=\operatorname{erfc}\left(\frac{\delta}{2 \sqrt{D t_{k}}}\right)-\exp \left(h^{2} D t_{k}+h \delta\right) \cdot \operatorname{erfc}\left(\frac{\delta}{2 \sqrt{D t_{k}}}+h \sqrt{D t_{k}}\right)
$$

where $t_{k}$ represents the carburising time, $h=K / D$, represents the relative coefficient of mass transfer, $\mathrm{K}$ - is the global coefficient of mass transfer in the case hardening medium; $\mathrm{D}$ - the diffusion coefficient of carbon in austenite.

c. For the Jominy hardenability curbes (c) have been deduced by E. Just [6] several regression equations having the general form:

$$
J_{d}=A \sqrt{C}-B d^{2} \sqrt{C}+D d-E \sqrt{d}+\sum k_{i} c_{i}-F N-G
$$

where $\mathrm{C}$ is the carbon content of steel, [\% $\mathrm{C}], \mathrm{c}_{\mathrm{i}}$ - content of alloying elements in steel [\% $\left.\mathrm{E}\right]$, $\mathrm{d}$ - distance from the quenched end of the Jominy test sample [mm], $\mathrm{N}$ - the ASTM score of the austenitic grain; A, B, D, E, F and G are the regression coefficients and $\mathrm{J}_{\mathrm{d}}$ the HRC hardness at the $\mathrm{d}$ distance in the Jominy test sample.

Replacing the $\mathrm{d}$ distance with the equivalent Jominy distance $\mathrm{E}$ and $\mathrm{J}_{\mathrm{d}}$ with $\mathrm{HRC}_{(\mathrm{E})}$, can be retained the following three Just formulas, used also in other literature [4] - [7]: 


$$
\begin{gathered}
\operatorname{HRC}_{(E)}=98 \sqrt{C}-0.01 E^{2} \sqrt{C}+1.79 E-19 \sqrt{E}+(19 M n+20 C r+6.4 N i+34 M o)-7 \\
H R C_{(E)}=88 \sqrt{C}-0.0053 E^{2} \sqrt{C}+1.32 E-15.8 \sqrt{E}+(5 S i+16 M n+19 C r+6.3 N i+35 M o)-0.82 N-2
\end{gathered}
$$

These relations are valid for the following limits of carbon and alloying elements concentrations: $0.08 \% \leq \mathrm{C} \leq 0.56 \%$; $\mathrm{Si} \leq 3.8 \%$; $\mathrm{Mn} \leq 1.88 \%$; $\mathrm{Cr} \leq 1.97 \%$; $\mathrm{Ni} \leq 8.94 \%$; $\mathrm{Mo} \leq 0.53 \%$ and for an austenitic score in the limits $1.5 \leq \mathrm{N} \leq 11$

$$
H R C_{(E)}=102 \sqrt{C}+1.102 E-15,47 \sqrt{E}+(21 M n+22 C r+7 N i+33 M o)-16
$$

relation valid for the steels with $0.25 \leq \% \mathrm{C} \leq 0.60$ and with the admissible alloying elements concentrations given by relations no. (25-26). The three relations produce results significantly closer each to another and also very close to those provided by the graphical dependencies for a series of German steels presented in the work [7]. Therefore, it was adopted for explaining of the hardenability curve the relation no. (27) is written as:

$$
H R C_{(E)}=102 \sqrt{C}+1.102 E-15.47 \sqrt{E}+S-16
$$

where

$$
S=21 M n+22 \mathrm{Cr}+7 \mathrm{Ni}+33 \mathrm{Mo}
$$

In connection with the application of relation (ec.28), have to be specified that the $\mathrm{HRC}_{(\mathrm{E})}$ may not exceed a certain maximum value, which is corresponding to the hardness of the

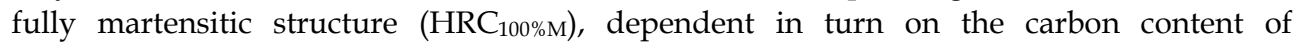
martensite (austenite which is totally transformed into quenching martensite). To calculate the maximum hardness E. Just proposed the relation:

$$
H R C_{100 M}=29+51 C^{0,7}
$$

which is applicable to steels with carbon content in the limits $0.1 \% \leq \mathrm{C} \leq 0.6 \%$.

Besides relation (30), in the speciality literature are presented also other relations, including the most complex relation specified in ASTM A 255 / 1989 with the polynomial expression:

$$
H R C_{100 M}=35.395+6.99 C+312.33 C^{2}-821.74 C^{3}+1015.48 C^{4}-538.34 C^{5}
$$

applicable to steel with $\mathrm{C} \leq 0.7 \%$.

On the other hand, in the technical literature are published more data under graphical form, where are presented the hardnesses of quenching structures, experimentally determined, depending on the carbon content and the proportion of martensite in the hardening structure (Table 2). The charts from where the data from Table 2 were taken, suggest that the hardness of the quenching structures increases with carbon content in steel after curves that have the tendency to be closed to some limits values at high carbon contents. Starting from this observation, it was considered that the most appropriate analytical expression of the hardness dependence on carbon content can be obtained by using a prognosis function with tendency of "saturation". 


\begin{tabular}{|c|c|c|c|c|c|c|c|c|c|}
\hline \multirow{2}{*}{$\%$ martensite } & \multirow{2}{*}{ Quoted ref. } & \multicolumn{8}{|c|}{ HRC hardness,at carbon content, $\%$} \\
\hline & & 0.1 & 0.2 & 0.3 & 0.4 & 0.5 & 0.6 & 0.7 & 0.8 \\
\hline \multirow{7}{*}{$100 \mathrm{M}$} & [a] & 38.5 & 44 & 50.5 & 56 & 60 & 62.5 & 64.5 & 66 \\
\hline & [b] & 37 & 44.5 & 51 & 56 & 61 & 63.5 & 65 & 66.5 \\
\hline & [c] & 36 & 45 & 52 & 57 & 60 & 62.5 & 64.5 & 66 \\
\hline & [d] & 36 & 44 & 50 & 55 & 59 & 63 & 65 & 66.5 \\
\hline & [e] & 38.5 & 44.2 & 50.3 & 56.1 & 60.9 & 64.2 & 64.8 & - \\
\hline & [f] & 39 & 45.5 & 51 & 55.8 & 60.4 & 64.6 & - & - \\
\hline & ref.average & 37.5 & 44.5 & 50.8 & 56 & 60.2 & 63.4 & 64.7 & 66.2 \\
\hline $95 \mathrm{M}$ & [d] & 33 & 40 & 47 & 52.5 & 57 & 61 & - & - \\
\hline $90 \mathrm{M}$ & [d] & 31 & 38 & 44.5 & 50.5 & 54.5 & 57.5 & - & - \\
\hline $80 \mathrm{M}$ & [d] & 28 & 35 & 41 & 46.5 & 50.5 & 54.5 & - & - \\
\hline \multirow{3}{*}{$50 \mathrm{M}$} & [a] & - & 32.5 & 36 & 41.5 & 47 & 51.5 & 53 & 54 \\
\hline & [e] & 26.2 & 30.7 & 37.5 & 42.4 & 46.6 & 50.7 & 53 & - \\
\hline & Average of ref. & 26.2 & 31.6 & 36.7 & 42 & 46.8 & 51.1 & 53 & 54 \\
\hline
\end{tabular}

[a] Hodge -Orehovski(average diagram);[b] Boyd-Field; [c] G.Krauss; [d] Metals Handbook; [e] ASTM 255(relation (31)); [f]E. Just(relation(30))

Table 2. The hardness of quenching structures according to different references.

In this purpose, the data from the Table 2 were used and exponential, logharitmic and logistic functions were explored, their graphics having the ordinate at origin different from zero and positive (is known the fact that the technical iron can be quenched to a structure of "massive" acicular ferrite, close to the martensite with low carbon and which, according to relation (31) has the value 35.395 HRC. Among the explored functions, the most closed results to the results given in the technical literature, referring to the hardness of the complete martensitic structure, have been obtained with the logistic function:

$$
y=\frac{K}{1+a e^{-b x}}
$$

and with the Johnson function:

$$
\ln y=K-\frac{a}{b+x}
$$

and their principle graphics being shown in Fig. 10.
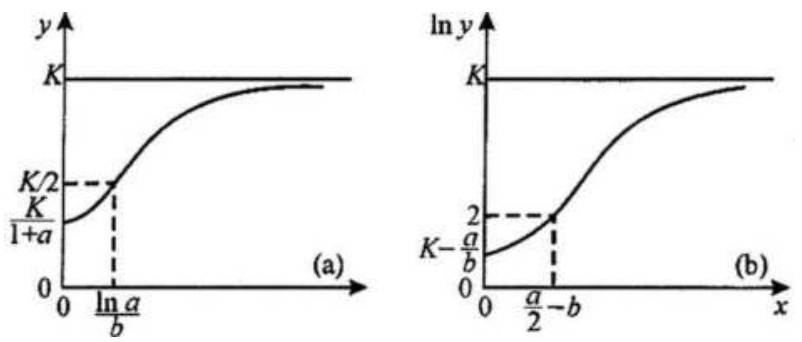

Fig. 10. The principle graphics of the logistic function (a) and Johnson function (b). 
For the hardness of the complete martensitic structure, the two functions mentioned above have the particular forms:

$$
\begin{aligned}
H R C_{100 M} & =\frac{70}{1+1.35 \exp (-4,24 C)} \\
\mathrm{HRC}_{100 \mathrm{M}} & =\exp \left(4.55-\frac{0.36}{0.27+\mathrm{C}}\right)
\end{aligned}
$$

The formulas no. (34) and (35) give results very close each to another and also close to the experimental data referring to steels with carbon content in the limits $0.1 \sim 0.8 \%$.

Furthermore the Johnson function can be used with satisfactory results also for the calculation of the hardness of the quenched layers in which the martensite proportion decreases to $50 \%$.

The general calculation relation and the auxiliary relations are shown in Fig.11.

Whereas in many literature works the hardness is expressed in Vickers units, is necessary also a Rockwell-Vickers equivalence relation. In this purpose, mathematical tables and graphics equivalence HRC-HV - were processed and the following relation have been obtained, depending on the load used to determine the Vickers hardness:

- $\quad$ for loads $\mathrm{F} \leq 1 \mathrm{Kgf}(9,8 \mathrm{~N})$

a. $\quad H R C=193 \lg H V-21.4 \lg ^{2} H V-316$

b. $\lg H V=\frac{193-\sqrt{10200-85.6 H R C}}{42.8}$

- for loads $\mathrm{F} \geq 5 \mathrm{Kgf}(49 \mathrm{~N})$

a. $\quad H R C=144.2 \lg H V-12.26 \lg ^{2} H V-252$

b. $\lg H V=\frac{144.2-\sqrt{8436-49 H R C}}{24.5}$

Concerning the data provided by the graphical dependencies and relations from Fig.11 it must be specified that these are referring to the "ideal case" in which cooling of the austenite subject to quenching is achieved below $M_{f}$ temperature, who, like the $M_{s}$ temperature decreases with the increasing of steel carbon content (austenite) and becomes negative at higher carbon concentrations than $0.6 \%$. In this case, if the austenite is cooled to room temperature or even above, in structure will remain a significant proportion of residual austenite, which decreases the hardness below the level indicated by the curves in Fig.11.

Typically, the proportion of residual austenite is calculated by Koistinen-Marburger relation:

$$
\% A_{r e z}=100 \exp [-0.011(M s-20)]
$$

where the Ms point temperature can be calculated using the Brandis relation:

$$
M_{S}=548-440 C-(14 S i+26 M n+11 C r+14 N i+9 M o)
$$




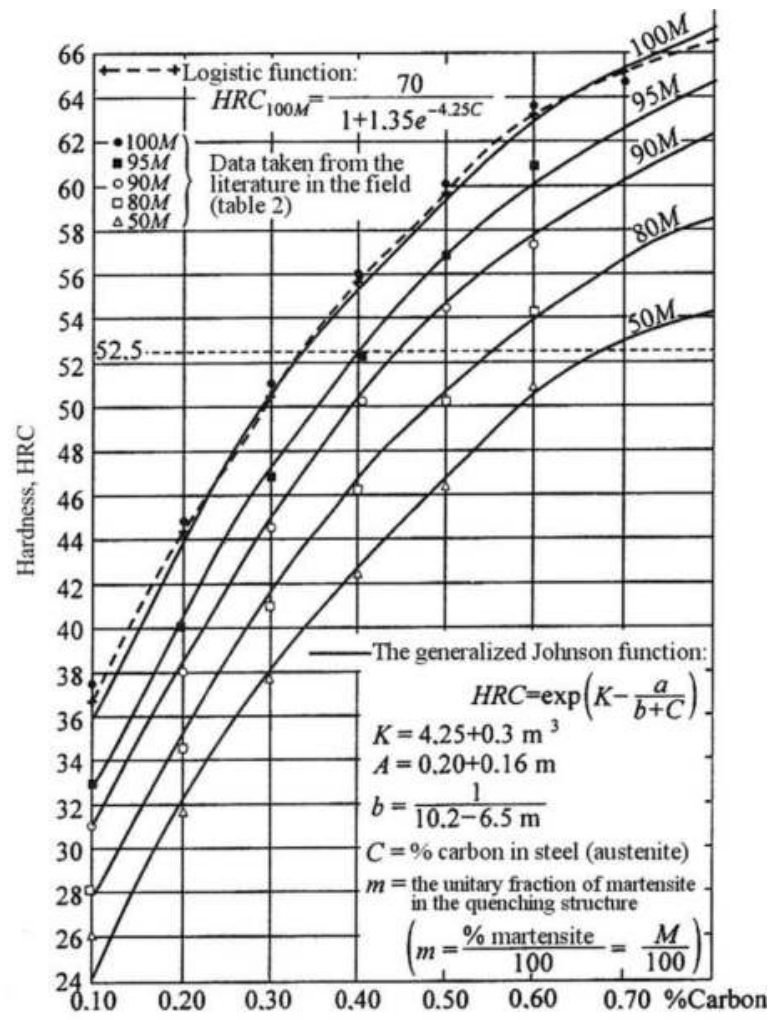

Fig. 11. The hardness of the quenching structures depending on carbon content of steel (austenite) and on the martensite proportion from the structure; continuous curves drawn up with Johnsonunction; dashed curves _ _ _ _ drawn up with logistical function.

Decreasing of hardness caused by the presence of residual austenite can be calculated with the relation:

a. $\quad \Delta H V \approx \frac{\% A_{r e z}}{0.10+0.015\left(\% A_{r e z}\right)}$

derived from data provided by G. Krauss for hardnesses of fully martensitic structures (at cooling under the temperature corresponding to the end of martensitic transformation - $\mathrm{M}_{\mathrm{f}}$ ) and the structures formed by martensite and residual austenite (at cooling to room temperature). If the hardness of carburized layer is measured in Rockwell units the indicative relation can be used:

b. $\quad \triangle H R C \approx \frac{\% A_{r e z}}{1+0.2\left(\% A_{r e z}\right)}$

Returning to the analytical solution of the correlation between Jominy sample and real parts, which should finally allow to draw the hardness curve of the carburized and quenched 
layer, is noted that this solution is materialized in a mathematical model of post carburising quenching, whose solving algorithm is based on knowing of the initial data referring to the following independent variables:

a. chemical composition of steel, respectively the alloying factor;

$$
S=21 \mathrm{Mn}+22 \mathrm{Cr}+7 \mathrm{Ni}+33 \mathrm{Mo}
$$

b. the geometry of parts subject to carburising, respectively the equivalent diameter $\mathrm{D}_{\text {ech; }}$;

c. the cooling intensity of the quenching medium, respectively the Grossmann $(\mathrm{H})$ relative cooling intensity;

d. the requested effective hardness $\left(\mathrm{HRC}_{\mathrm{ef}}\right)$;

e. the requested effective case $\operatorname{depth}\left(\delta_{\mathrm{ef}}\right)$.

Starting from this initial data, the algorithm for determining of the hardness curve of carburized and quenched layer will require the following sequence of steps:

Step I taking into account the geometry of parts subject to processing, the equivalent diameter $\mathrm{D}_{\text {ech }}$ is calculated with one of the equivalence relations mentioned in Fig.1.

Step II taking into account $D_{\text {ech }}$ and $h$, is calculated the equivalent distance $E$ from the frontal quenched end of the Jominy sample by means of the relation (19), written under the form:

$$
\mathrm{E}=\mathrm{D}_{\text {ech }}^{\left(0.755-0.0003 \mathrm{D}_{\text {ech }}\right)}-\mathrm{D}_{\text {ech }}\left(\frac{\mathrm{H}-0.25}{3 \mathrm{H}-0.25}\right)
$$

Step III taking into account $\mathrm{E}$ and $\mathrm{S}$ and giving to the hardness the value $\mathrm{HRC}_{\mathrm{ef}}$, can be calculated the effective carbon content $C_{\text {ef }}$ by means of relation (28), written under the form:

$$
H R C_{e f}=102 \sqrt{C_{e f}}+1.1 E-15.47 \sqrt{E}+S-16
$$

which lead to the relation:

$$
\mathrm{C}_{\mathrm{ef}}=\left[\frac{\left(\mathrm{HRC}_{\mathrm{ef}}+16-\mathrm{S}\right)+15.47 \sqrt{\mathrm{E}}-1.1 \mathrm{E}}{102}\right]^{2}
$$

In the technical literature and in industrial practice of carburising followed by quenching, for the actual hardness value is used most frequently $\mathrm{HRC}_{\mathrm{ef}}=52.5$ (ie $\mathrm{HV}_{\mathrm{ef}}=550$ ). Using this value, the equation (44) takes the following particular form:

$$
\mathrm{C}_{\text {ef } 52.5 \mathrm{HRC}(550 \mathrm{HV})}=\left[\frac{(68.5-\mathrm{S})+(15.47 \sqrt{\mathrm{E}}-1.1 \mathrm{E})}{102}\right]^{2}
$$

U.Wyss had drawn the curves (parabola) $C_{e f 52.5 H R C}=f(E, S)$ for several German case hardening steels (Fig.12) with the average chemical composition (according to DIN-tab.3), without mentioning of the calculation formula or the effective values of the alloying factors $\mathrm{S}$. 


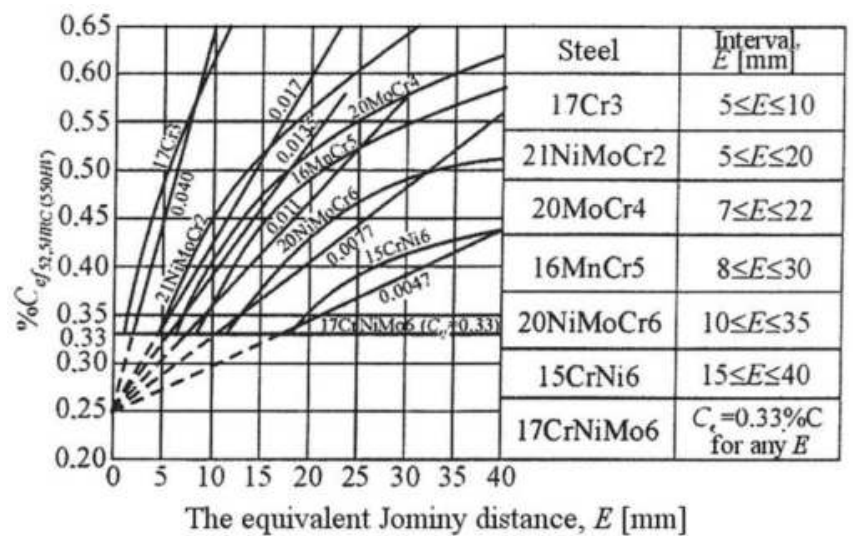

Fig. 12. Correlation between the effective carbon content and the Jominy equivalent distance for different German steels with the average standard chemical composition[4].

In addition, U. Wyss suggested the using of a linear relation to calculate the actual carbon content as it follows:

$$
C_{e f, 52.5 H R C}=0.25+f_{c} E
$$

In which the slope $f_{c}$ is a hardenability factor of steel, having the values written on the corresponding lines, drawn in Fig.12.

In connection with this approach of the problem, it is observed that the use of relation (46) is possible only for certain intervals corresponding to equivalent distance $\mathrm{E}$, intervals on which the value obtained for $\mathrm{C}_{\text {ef } 52.5}$ is not lower than $0.33 \%$ and is not different more than $\pm 0.03 \%$ in rapport with curve (parable) replaced by the line corresponding to a given steel. These limits for $\mathrm{E}$ are mentioned also in the table placed on the right of Fig. 12.

In the work has been calculated the effective carbon content with formula (45), both for the German steels and also for the Romanian steels having an average chemical composition according to DIN and STAS (Table 3), using for the calculation of the alloying factor the relation $\mathrm{S}=21 \mathrm{Mn}+22 \mathrm{Cr}+7 \mathrm{Ni}+33 \mathrm{Mo}$. The variation of the effective carbon content with the Jominy equivalent distance for the specified steels is shown in Fig. 13.

The analysis of the curves from Fig.13 led to following conclusions:

a. for the steels with close values of the alloying factor, $\mathrm{S}$, the curves are close positioned or even overlapped (case of $20 \mathrm{MoNi} 35,16 \mathrm{MnCr} 5,18 \mathrm{MnCr} 10$ and $21 \mathrm{TiMnCr} 12$ steels, having $S=44.3 \sim 45.25$ and of the steels $15 \mathrm{CrNi} 6$ şi $21 \mathrm{MoMnCr} 12$, having $\mathrm{S} 55.55$ );

b. the ordinates at origin and the rate of curves are strongly decreasing with the increasing of the value of the alloying factor, S. As a result, the curves can be replaced with straight lines with different slope, but also with ordinates having different origins, both being dependent of alloying factor S. Putting the condition that the replacing lines do not lead to deviations higher than $\pm 0,03 \% \mathrm{C}$, the generalized equation of these lines was:

$$
C_{e f 52.5}=C_{e f 0}+f_{c} E
$$


where the ordinate at origin $C_{\text {efo }}$ and the slope $f_{c}$ are dependent on the alloying factor $S$, respectively:

$$
\begin{gathered}
C_{e f 0}=0.41-0,005 S \\
f_{c}=6,5 e^{-1.6 \ln S}
\end{gathered}
$$

\begin{tabular}{|c|c|c|c|c|c|c|c|}
\hline \multirow{2}{*}{ Steel grade } & \multicolumn{6}{|c|}{ The average chemical composition, $\%$} & \multirow{2}{*}{$\begin{array}{l}\text { Alloying } \\
\text { factor, S }\end{array}$} \\
\hline & $\mathrm{C}$ & $\mathrm{Mn}$ & $\mathrm{Cr}$ & $\mathrm{Ni}$ & Mo & $\mathrm{Ti}$ & \\
\hline $15 \mathrm{Cr} 3$ & 0.15 & 0.50 & 0.65 & - & - & - & 25.30 \\
\hline $15 \mathrm{Cr} 08$ & 0.15 & 0.55 & 0.85 & - & - & - & 30.25 \\
\hline 21NiMoCr2 & 0.21 & 0.80 & 0.50 & 0.55 & 0.20 & - & 38.25 \\
\hline $20 \mathrm{MoCr} 4$ & 0.20 & 0.75 & 0.40 & - & 0.45 & - & 39.40 \\
\hline $16 \mathrm{MnCr} 5$ & 0.16 & 1.15 & 0.95 & - & - & - & 45.05 \\
\hline 18MnCr10 & 0.18 & 1.05 & 1.05 & - & - & - & 45.15 \\
\hline 21TiMnCr12 & 0.21 & 0.95 & 1.15 & - & - & 0.07 & 45.25 \\
\hline 20MoNi35 & 0.20 & 0.55 & - & 3.50 & 0.25 & - & 44.30 \\
\hline $13 \mathrm{CrNi30}$ & 0.13 & 0.45 & 0.75 & 2.95 & - & - & 46.60 \\
\hline 20NiMoCr6 & 0.20 & 0.60 & 0.70 & 1.50 & 0.30 & - & 48.40 \\
\hline 15CrNi6 & 0.15 & 0.50 & 1.55 & 1.55 & - & - & 55.45 \\
\hline 21MoMnCr12 & 0.21 & 1.00 & 1.20 & - & 0.25 & - & 55.65 \\
\hline 17CrNiMo6 & 0.17 & 0.50 & 1.65 & 1.55 & 0.30 & - & 67.55 \\
\hline
\end{tabular}

Table 3. The average chemical compositions and the alloying factor $\mathrm{S}$ of the standardized German and Romanian case hardening steels.

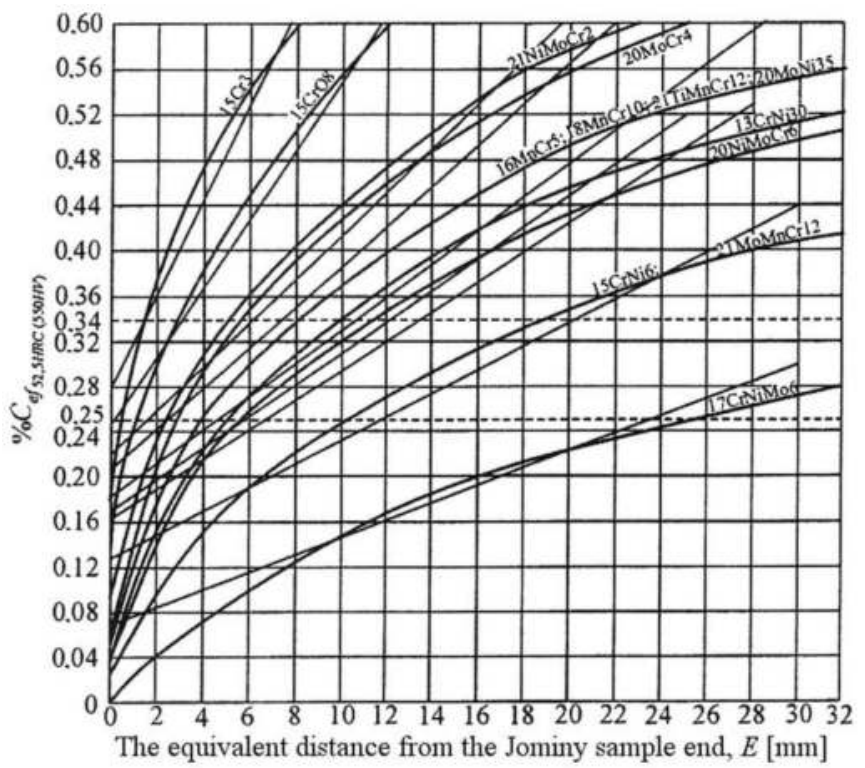

Fig. 13. The variation of the effective carbon content $C_{\text {ef52,5 }}$ with $E$ for German and Romanian steels, having the average chemical composition (in the limits of the grade). 
The particular values of these elements and the applicable intervals of the linearizing relation for the standardized case hardening steels are given inTable 4.

\begin{tabular}{|c|c|c|c|c|}
\hline Steel & Alloying factor,S & $C_{e f 0}$ & $f_{c}$ & E interval $^{*}\left(\% \mathrm{C}_{\mathrm{ef}}\right)$ \\
\hline 15Cr3 & 25.30 & 0.28 & 0.043 & $4(0.45) \sim 7(0.58)$ \\
\hline 15Cr08 & 30.25 & 0.26 & 0.030 & $4(0.38) \sim 10(0.56)$ \\
\hline 21NiMoCr2 & 38.25 & 0.22 & 0.0195 & $4(0.30) \sim 18(0.57)$ \\
\hline 20MnCr4 & 39.40 & 0.21 & 0.018 & $4(0.28) \sim 20(0.57)$ \\
\hline $\begin{array}{c}\text { 20MoNi35 } \\
\text { 16MnCr5 } \\
\text { 18MnCr10 }\end{array}$ & 45 & 0.185 & 0.0145 & $4(0.24) \sim 26(0.56)$ \\
21TiMnCr12 & & & & \\
\hline 13CrNi30 & 46.6 & 0.18 & 0.014 & $4(0.24) \sim 25(0.52)$ \\
\hline 20NiMoCr6 & 48.4 & 0.17 & 0.013 & $4(0.22) \sim 25(0.50)$ \\
\hline $\begin{array}{c}\text { 15CrNi6 } \\
\text { 21MoMnCr12 }\end{array}$ & 55.5 & 0.13 & 0.0105 & $4(0.17) \sim 30(0.44)$ \\
\hline 17CrNiMo6 & 67.5 & 0.07 & 0.0077 & $4(0.10) \sim 30(0.30)$ \\
\hline
\end{tabular}

*For $E$ have been taken values as $E \geq 4 \mathrm{~mm}$, imposed by the E.Just rel and rel.(19)

Table 4. The values of parameters $C_{e f 0}, f_{c}$ and the intervals for $E$ in which is applied the linearizing relation (47) for the German and Romanian steels with medium standardized chemical composition.

In fact, the effective carbon content can has lower values than those ensuring a certain minimum proportion of quenching martensite. If in Fig.11 will be drawn the horizontal corresponding to the effective hardness of $52.5 \mathrm{HRC}$ can be found that this value is assured by the following combinations of effective carbon contents and respectively martensite percentages in the hardening structure:

$\begin{array}{cccccc}\% \text { Martensite }(\mathrm{M}) & 100 & 95 & 90 & 80 & 50 \\ \% C_{\text {ef } 52.5} & 0.34 & 0.40 & 0.45 & 0.56 & 0.70\end{array}$

On the interval $80 \leq \mathrm{M} \leq 100 \%$, the effective carbon content has a lineraly variation with the martensite proportion, according to relation:

$$
\% C_{e f 52.5}=1,44-0,011 M
$$

Setting the condition that for the effective case depth the actual proportion of martensite to be within the required range (to provide appropriate mechanical characteristics of the carburized and quenched layer), can be noted that the maximum amount of the effective carbon content should not exceed $0,56 \%$ (value which is close to the carbon surface content of about $0.8 \%$, with a drastic reduction of the carburizing depth, particularly in steels with low hardenability, respectively with an alloying factor $S \leq 30$ ). On the other hand, the value of the $C_{\text {ef } 52,5}$ will not decrease more below $0.34 \% C$ because even the quenching structure for the effective depth is fully martensitic, its hardness decreases significantly below the set value (52.5HRC). This is the reason for why U.Wyss adopted for the $17 \mathrm{CrNiMo6}$ steel the 
amount $\mathrm{C}_{\mathrm{ef}}=0.33 \%$, although in the carburized layer of steel, the information offered by relation (45) and Fig.13 shown that the hardness of 52.5HRC can be obtained even for the content of $0.17 \% \mathrm{C}$ of core (at $\mathrm{E}=13 \mathrm{~mm}$ ). In a subsequent paper [7], Weissohn and Roempler suggest as minimum value for the carbon content with the concentration of $0.28 \%$ (for which HRC $_{100 \mathrm{M}} \sim 49.4$, according to Fig.11). Adopting a value below that of the $0.34 \%$ could be justified for alloyed steel intended for carburising, due to the fact that alloyed martensite has a hardness higher with 1 2HRC than that of unalloyed steels.

In conclusion, for the calculation of the effective carbon content $\left(C_{e f, 52.5 \mathrm{HRC}}\right)$ can be used the linearizing relations (47-49), with supplementary restrictions:

a. $\mathrm{E} \geq 4 \mathrm{~mm}$

b. $0,28 \leq C_{e f, 52.5 H R C} \leq 0.56 \%$ (respectively $100 \geq \mathrm{M} \geq 80 \%$ )

Step IV Using $\mathrm{C}_{\mathrm{ef}}$ and $\delta_{\mathrm{ef}}$, can be calculated the carburising time $\left(\mathrm{t}_{\mathrm{k}}\right)$ at isothermal carburising with a single cycle or the active carburising time $\left(t_{k}\right)$,respectively the diffusion time $\left(t_{D}\right)$, at carburising in two steps. The performing of this calculation supposes the knowing of thermal regime $\left(t_{k}, t_{D}\right)$, the chemical regime $\left(C_{\text {potK }}, C_{\text {pot }} \mathrm{D}\right)$, the corresponding evaluation of the global mass transfer in the carburising medium (K); and the diffusion coefficient of carbon in austenite (D).

Step $\mathbf{V}$ is based on knowing of the carbon profile and of the cooling law (curve) of the layer and has as final purpose the drawing of the layer hardness profile. The carbon profile can be determined after the step IV, and the cooling curve of layer can be drawn using the relation (11).

The most direct method for determining and drawing of the hardness profile consist in overlapping of the cooling curve of the case hardened layer on the transformation diagrams of continuous cooling of austenite (CCT diagrams) "of different steels" from the layer, steels with carbon content that decreases from surface to core. The method is illustrated in Fig.14, for the case where the diagrams for the austenite transformation, corresponding for three steels with different carbon content that will be carburized, are known:

a. with carbon content of core, $\mathrm{C}_{\mathrm{m}}$;

b. with effective carbon content, $\mathrm{C}_{\mathrm{ef}}$;

c. with carbon content of surface, $\mathrm{Cs}$

Because the temperatures corresponding to Ms point and the transformation ranges for the three diagrams are placed differently in the plane T- $t$ (at a lower position and to the right, as the carbon content increases), the intersections of these with the cooling curve led to different structures (decreasing of the proportions of bainite and increasing of the proportions of martensite), respectively with different hardnesses $\left(\mathrm{HRC}_{\mathrm{m}}<\mathrm{HRC}_{\mathrm{ef}}<\mathrm{HRC}_{100 \mathrm{M}}\right.$

For an accurate drawing of the hardness profile, is necessary to know a minimum number of 5-6 austenite transformation diagrams, corresponding to different carbon contents for a steel having in its chemical composition, all the other elements that are permanently accompanying and alloying elements with the same contents. But, this kind of technical "archive" is not currently available, even in the richest databases for the usual casehardening steels. To overcome these difficulties can be used a hardness calculation method based on knowledge of chemical composition and of a kinetic parameter characteristic to cooling law of the case hardened layer. This parameter can be the cooling time at passing 
through a certain temperature enclosed between the austenitizing temperature $\left(T_{A}\right)$ and ambient temperature $\left(\mathrm{T}_{\mathrm{amb}}\right)$. Most of the kinetic parameters of this type are the times of passing through temperatures of $700^{\circ} \mathrm{C}, 500^{\circ} \mathrm{C}$ and $300^{\circ} \mathrm{C}$ respectively $t_{700,} t_{500}$ şi $t_{300}$, highlighted also on CCT diagrams in Fig. 14. Because the data in the literature in the field are referring usually to a temperature of $\mathrm{T}_{\mathrm{A}}=850^{\circ} \mathrm{C}$, the absolute parameters mentioned can be replaced with relative parameters $t_{0.825 T_{A}}, t_{0.59 T_{A}}$, respectively $t_{0.35 T_{A}}$. Besides these cooling times can be used also other kinetic parameters as are the cooling times between two given temperatures $\left(\Delta t_{500}^{T_{A}}, \Delta_{500}^{800}, \Delta_{300}^{700}\right)$, or the instantaneous cooling speeds at passing of the cooling curve through a temperature $\left(v_{750}, v_{700}, v_{500}, v_{300}\right)$, or the medium cooling speed in a temperature range $\left(\bar{v}_{300}\right)$. The advantage of using of these kinetic parameters is that can be built structural diagrams in coordinates T-lgt or T-lgv, in which the cooling curves are replaced by verticals lgt or lgv and on basis of these, also structural diagrams in coordinates $\%$ structural constituents - lgt (lgv).

\subsection{Method Maynier-Carsi}

In the works [8] and [9] is used a calculation method derived from the analysis of 251 diagrams of transformation of austenite at continuous cooling, method in where the kinetic factor taken in consideration is the instantaneous cooling speed at passing of the cooling curve through the temperature of $700^{\circ} \mathrm{C}$, respectively:

$$
v_{700}=\frac{T_{A}-700}{t_{700}}
$$

In the calculation, the authors have introduced also the austenitizing parameter:

$$
\mathrm{P}_{\mathrm{A}}=\left[\frac{1}{\mathrm{~T}_{\mathrm{A}}}-\frac{4.6}{\Delta \mathrm{H}} \ln \mathrm{t}_{\mathrm{A}}\right]^{-1}
$$

where $T_{A}$ represents the austenitizing temperature $[K], t_{A}$ is the austenitizing time $[h]$, with condition that $t_{A}<1 h$, and $\Delta \mathrm{H}$ the activation energy of the austenitization process $\left(\Delta \mathrm{H}=2.4 .10^{5}[\mathrm{cal} / \mathrm{molK}]\right.$ for steels with low than $0.04 \% \mathrm{Mo}$ şi $\Delta \mathrm{H}=4.2 .10^{5}$ [cal $/ \mathrm{molK}$ ] for steels with more than $0.04 \% \mathrm{Mo}$ ). The $\mathrm{P}_{\mathrm{A}}$ parameter determines, indirectly, the size of the austenitic grain, after the heating at $\mathrm{T}_{\mathrm{A}}$, in time $\mathrm{t}_{\mathrm{A}}$.

By means of statistical processing have been derived [5] the regression relations for ten critical cooling speeds named $v_{c r}, v_{100 M}, v_{90 M}, v_{50 M}, v_{10 M}, v_{1 M}, v_{1 F P}, v_{10 F P}, v_{50 F P}$, $v_{90 F P}, v_{100 F P}$ in which the figures shown the martensite proportions $(\mathrm{M})$, respectively ferrite and perlite (FP).

The regression relations have the following general form:

$$
\lg v_{c r}=C_{v}-\left(\sum K_{E_{i}} \cdot E_{i}+K_{A} \cdot P_{A}\right)
$$

in which $C_{V}$ is the speed constant, $K_{E i}$ - the influencing coefficient of Ei element, $P_{A}$ represents the austenitizing parameter, $\mathrm{K}_{\mathrm{A}^{-}}$the influencing coefficient of austenitizing 

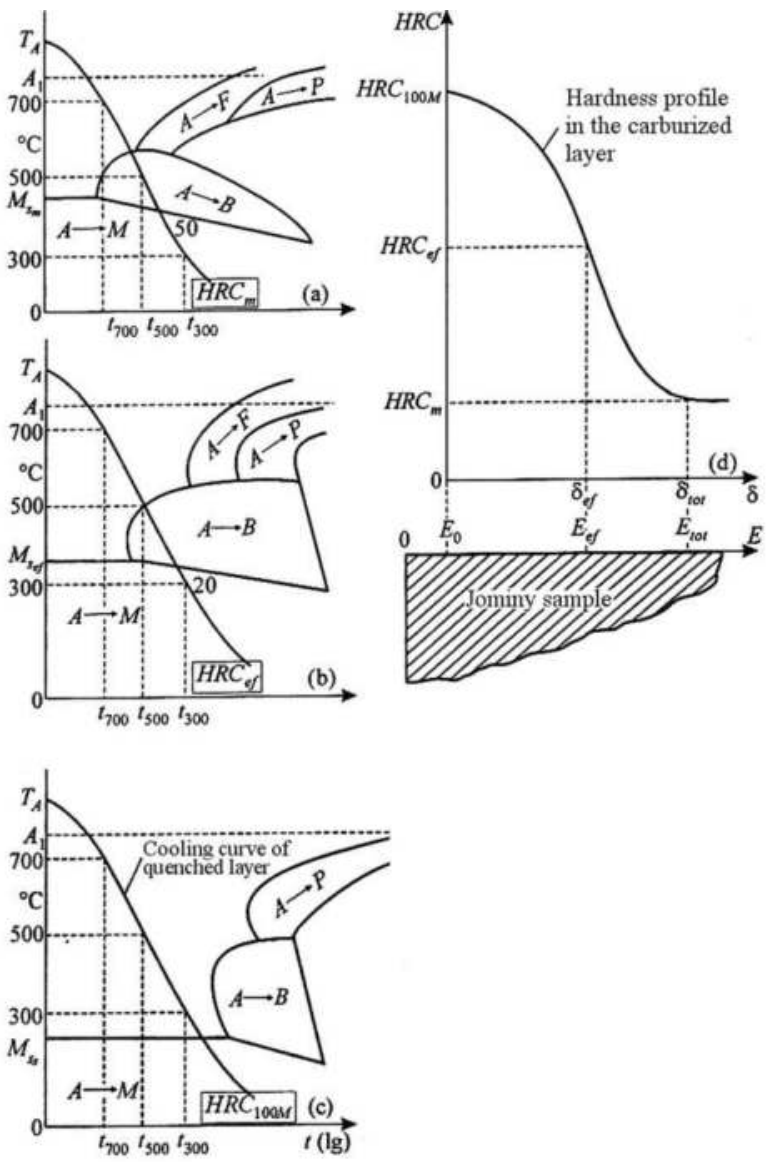

Fig. 14. Determination of the structure and hardness in different points in the carburized layer depth of the part and the Jominy sample. a) the CCT diagram of the not carburized core, with $\delta \geq d_{\text {tot }}$ and the core carbon content $C_{m} ; b$ ) the CCT diagram of the layer point at depth def, with carbon content of $\mathrm{C}_{\mathrm{ef}} ; \mathrm{c}$ ) the CCT diagram of the surface point of the part $(\delta=0)$ with surface carbon content $\left.C_{\text {ef }} ; d\right)$ hardness profile of the carburized layer in the part and the Jominy sample.

parameter (of the austenitic grain size), and Ei represent the proportion of carbon, adding elements and alloying elements.

The particular forms of the regression relations are given in Table 5, for the case in which these cooling speeds are expressed in $\left[{ }^{\circ} \mathrm{C} / \mathrm{h}\right]$. To use this calculation method is necessary to know the instantaneous cooling speed $\mathrm{v}_{700}$ in the case hardened layer and its dependency of this of equivalent distance $\mathrm{E}$ from the frontal quenched end of Jominy sample.

In this purpose, Popescu and Cojocaru [5] have used a diagram $v_{700}=f(E)$, taken from UNE7279 norm, having the ordinate $\mathrm{v}_{700}\left[{ }^{\circ} \mathrm{C} / \mathrm{s}\right]$ in logarithmic scale and the abscise $\mathrm{E}[\mathrm{mm}]$ in normal scale (Fig.15). 


\begin{tabular}{|c|c|c|c|c|c|c|c|}
\hline \multirow{2}{*}{$\lg v_{c r_{700}}$} & \multirow{2}{*}{$C_{v}$} & \multicolumn{5}{|c|}{$K_{E_{i}}$ for the element: } & \multirow{2}{*}{$K_{A}$} \\
\cline { 3 - 7 } & & $\mathrm{C}$ & $\mathrm{Mn}$ & $\mathrm{Ni}$ & $\mathrm{Cr}$ & $\mathrm{Mo}$ & \\
\hline $\lg v_{100 M}$ & 9.81 & 4.62 & 0.78 & 0.41 & 0.80 & 0.66 & 0.0018 \\
\hline $\lg v_{90 M}$ & 8.76 & 4.04 & 0.86 & 0.36 & 0.58 & 0.97 & 0.0010 \\
\hline $\lg v_{50 M}$ & 8.20 & 3.00 & 0.79 & 0.57 & 0.67 & 0.94 & 0.0012 \\
\hline $\lg v_{10 M}$ & 9.80 & 3.90 & $-0.54 M n++2.45 \sqrt{M n}$ & 0.46 & 0.50 & 1.16 & 0.0020 \\
\hline & 8.56 & 1.50 & 1.84 & 0.78 & 1.24 & 1.46 & 0.0020 \\
\hline $\lg v_{1 F P}$ & 10.55 & 4.80 & 0.80 & 0.72 & 1.07 & 1.58 & 0.0026 \\
\hline $\lg v_{10 F P}$ & 9.06 & 4.11 & 0.90 & 0.60 & 1.00 & 2.00 & 0.0013 \\
\hline $\lg v_{50 F P}$ & 8.04 & 3.40 & 1.15 & 0.96 & 1.00 & 2.00 & 0.0007 \\
\hline $\lg v_{90 F P}$ & 8.40 & 2.80 & 1.51 & 1.03 & 1.10 & 2.00 & 0.0014 \\
\hline $\lg v_{100 F P}$ & 8.56 & 1.50 & 1.84 & 0.78 & 1.24 & $2 \sqrt{M o}$ & 0.0020 \\
\hline
\end{tabular}

Table 5. The values of $C_{v}, K_{E_{i}}$ and $K_{A}\left(P_{A}\right.$ in $\left.{ }^{\circ} \mathrm{C}\right)$ from the regression relations (53)

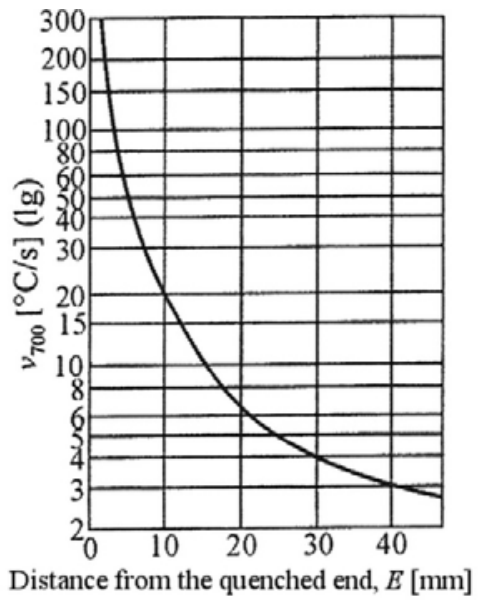

Fig. 15. Dependency of the instantaneous cooling speed $V_{700}$ on distance from the frontal quenched end of the Jominy sample (according to UNE 7279 [9].

The mathematical processing of data from this diagram shows that the function $v_{700}=f(E)$ has the form:

$$
\begin{gathered}
v_{700}=500 E^{-1.41}\left[{ }^{\circ} \mathrm{C} / \mathrm{s}\right] \\
v_{700}=1,8.10^{6} E^{-1.41}\left[{ }^{\circ} \mathrm{C} / \mathrm{h}\right]
\end{gathered}
$$

The two relations offer results in accordance with data of Fig. 15, for $1.5 \leq \mathrm{E} \leq 30 \mathrm{~mm}$.

Admitting that the austenitizing temperature, for the data shown in Fig. 15 is $\mathrm{T}_{\mathrm{A}}=850^{\circ} \mathrm{C}$ (which is not specified in the work [9], but is usually used in other works in the field), the absolute instantaneous cooling speed $\mathrm{V}_{700}$ can be replaced with the relative speed $\mathrm{V}$ 0,825TA, which will be calculated with the relation: 


$$
v_{0,825 T_{A}}=\frac{T_{A}-0.825 T_{A}}{t_{0.825 T_{A}}}=\frac{0.175 T_{A}}{t_{0.825 T_{A}}}
$$

Combining this relation with the relation (11), in which $\theta=0.825$, results:

$$
v_{0.825 T_{A}}=0.55 T_{A} \cdot E^{-1,41}
$$

For $\mathrm{T}_{\mathrm{A}}=850^{\circ} \mathrm{C}$, relation (57) led to $v_{700}=468 . E^{-1.41}$, value which is very close to that given by the relation(54), this is confirming also the validity of the relations (11) and (12).

Taking into account the critical speeds (calculated with the relations from Table 5) and the carbon profile curve of the carburized layer allow the overlapping of the structural diagrams at different carbon concentrations and taking into account the speed $\mathrm{v}_{700}\left(\mathrm{v}_{0,825 \mathrm{TA}}\right)$ of layer, allow the positioning of the vertical of this speed in the space of the structural diagram and the deriving of the proportions of the quenching constituents for each carbon content (respectively for each depth) of carburized layer.

\subsection{The Eckstein method}

In paper [10], another drawing method of the hardness profile curve is provided, which is considered to be described as a complex exponential function as it follows:

$$
H_{E}=H_{S} \cdot E^{b} \cdot e^{-c E}
$$

where $H_{S}$ is the surface hardness, respectively the martensite hardness which has the superficial carbon content $C_{s}, E$ is the equivalent Jominy distance in the depth of the case hardened layer, and $\mathrm{b}$ and $\mathrm{c}$ are the coefficients dependent on the steel chemical composition.

For the calculation of the Jominy equivalent distance, the author provides the formula:

$$
E=0.0877+0.761 t_{A / 5}-0.0148 t_{A / 5}^{2}+0.00012 t_{A / 5}^{3}
$$

where $t_{A / 5}$ represents the cooling time from austenitizing temperature in view of cooling, from $850^{\circ} \mathrm{C}$, until $500^{\circ} \mathrm{C}$.

The relation no.(59) is applicable for the case $t_{A / 5} \leq 42 \mathrm{~s}$ (maximum values for parts with the equivalent diameter $\mathrm{D} \leq 100 \mathrm{~mm}$, quenched in mineral oils with cooling intensity $0.25 \leq \mathrm{H} \leq 0.60)$.

Due to fact that $\mathrm{T}_{\mathrm{A}}=850^{\circ} \mathrm{C}$ and $\mathrm{T}_{\text {cooling }}=500^{\circ} \mathrm{C}$, results that the relative cooling temperature has the value $\theta_{\text {racire }}=\frac{500}{850}=0.59$ and the time $t_{A / 5}$ can be replaced with time $t_{0.59 T_{A}}$, usable for each austenitizing temperature in view of cooling, $\mathrm{T}_{\mathrm{A}}$. With this specification, the relation (11) can be used, from where, through the replacement $\theta_{(E, t)}=0.59$ and through variable changing, can be obtained the relation:

$$
E=1.24 t_{0,59 T_{A}}^{0,71}
$$


In Fig. 16 is graphically shown the dependency $E=f\left(t_{0.59 T_{A}}\right)$ determined with relations (59) and (60), from where results that these have led to identical results for $E \leq 25 \mathrm{~mm}$ and very close results for the range $25 \leq \mathrm{E} \leq 40 \mathrm{~mm}$.

Due to fact that in both relations, the independent variable is the cooling time $t_{0.59 T_{A}}$, become necessary to find a modality for calculation of this time depending on part diameter , D, on cooling intensity of the quenching medium, $\mathrm{H}$ and on the carburising depth $\delta$. In this purpose, were used the data provided by the graphical dependencies from work [10], referring to the experimental determination of the time $t_{A / 5}$ in accordance with the carburising depth $\delta$, which are combined with the data provided by Fig. 16 and 6 of the work. From this processing was derived, in a first and acceptable approximation, the cooling time from austenitizing temperature $\mathrm{T}_{\mathrm{A}}$ until temperature $\mathrm{T}=0.59 \mathrm{~T}_{\mathrm{A}}$ having a linearly dependence on $\delta$ depth, respectively:

$$
\mathrm{t}_{0.59 \mathrm{~T}_{\mathrm{A}}}=\mathrm{t}_{0}+\mathrm{m} \delta[\mathrm{s}]
$$

with

$$
t_{0}=13.6+0.36 D-23.4 H-0.126 D H
$$

$$
m=0.177 D^{0.575}
$$

where $\mathrm{D}$ is the part diameter $[\mathrm{mm}]$, and $\mathrm{H}$ is the relative cooling intensity of the quenching medium.

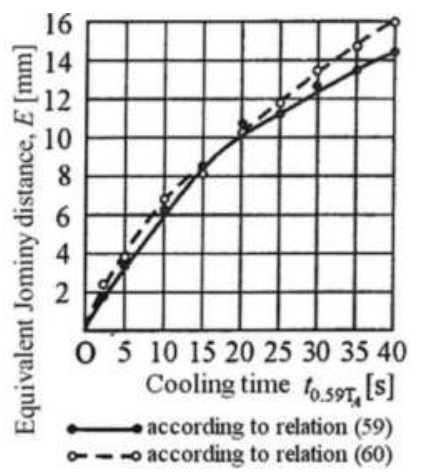

Fig. 16. The dependence of the Jominy equivalent distance and the cooling time from the austenitizing temperature $\mathrm{T}_{\mathrm{A}}$ to the temperature of $\mathrm{T}=0,59 \mathrm{~T}_{\mathrm{A}}\left(t_{0.59 \mathrm{~T}_{A}}\right.$ or $t_{A / 5}$ for $\left.\mathrm{T}_{\mathrm{A}}=850^{\circ} \mathrm{C}\right)$.

In order to properly use the relation (58), the b and c coefficients also have to be known; for these coefficients no information is available in the technical literature, including the work [10].

In conclusion, the effects of post carburising quenching process can be quantified by the calculation algorithm required by Maynier-Carsi, but corrections have to be applied; these corrections are determined by the presence of residual austenite and its presence implication on the hardness in the superficial layer; the obtained algorithm allows the very easily determination of the information regarding the effects of the carburising and quenching process on layer characteristics, starting from information provided by Jominy test. 
Algorithm for developing of software dedicated to the estimation of the carburising effects

$\mathrm{HV}=\mathrm{f}(\% \mathrm{C})$;

$\mathrm{HV}=\mathrm{F}$ (distance from the surface of the carburized layer)

\section{Input data}

- Steel chemical composition;

- Equivalent diameter, Dech, cm;

Equalization relations

Dech. $=1,1 \mathrm{~h}$ (for a square section, $\mathrm{h}$ is the section side)

D circular sections

$\mathrm{D}=1.33 \mathrm{~h}$ for rectangular sections with $\mathrm{b} \geq 1,5 \mathrm{~h}$;

- Cooling intensity, $\mathrm{H}$;

- Effective hardness, HRC $_{\text {ef }}$ (52.5 HRC);

- Requested effective carburized depth, $\delta_{\mathrm{ef}}, \mathrm{cm}$;

- Diffusion coefficient, D, $\mathrm{cm}^{2} / \mathrm{s}$;

- Austenitizing temperature, $\mathrm{T}_{\mathrm{A}}\left[{ }^{\circ} \mathrm{C}\right]$;

- Austenitizing time, $\mathrm{t}_{\mathrm{A}}[\mathrm{h}]$ (maximum $0.5 \mathrm{~h}$ );

- Carburising temperature, $\mathrm{T}_{\mathrm{K}}, \mathrm{K}$;

- Carbon concentration at the surface of the carburized layer, $\mathrm{Cs}=0.8 \%$.

\section{STEPS}

\section{START}

$\mathbf{1}^{\circ}$ Calculates the equivalent distance from the frontal quenched end of the Jominy sample,

E

$E=\operatorname{Dech}^{(0.755-0.0003 D s c h)}-\operatorname{Dech} \frac{H-0.25}{3 H-0.25}[\mathrm{~cm}] ;$

$2^{\circ}$ Calculates the alloying factor, $\mathrm{S}$

$S=21 \mathrm{Mn}+22 \mathrm{Cr}+7 \mathrm{Ni}+33 \mathrm{Mo}$;

$3^{\circ}$ Calculates the carbon effective concentration, Cef, corresponding to effective hardness

$C_{e f 52.5 H R C(550 H V)}=\left[\frac{(68.5-S)+(15,47 \sqrt{E}-1.1 E)}{10^{2}}\right]^{2} ;$

$4^{\circ}$ Calculates the austenitizing parameter, $\mathrm{P}_{\mathrm{A}}$;

If $\% \mathrm{Mo}<0,04 \quad$ If $\% \mathrm{Mo}>0,04$

$\mathrm{P}_{\mathrm{A}}=\left[\frac{1}{\mathrm{~T}_{\mathrm{A}}+273}-1.961 .10^{-5} \ln \mathrm{t}_{\mathrm{A}}\right]^{-1} \mathrm{P}_{\mathrm{A}}=\left[\frac{1}{\mathrm{~T}_{\mathrm{A}}+273}-1.095 .10^{-5} \ln \mathrm{t}_{\mathrm{A}}\right]^{-1}$ 
$5^{\circ}$ Calculates the logarithm of critical cooling speeds $\log _{700}$ for the constituents percentages: $100 \% \mathrm{M}, 90 \% \mathrm{M}, 50 \% \mathrm{M}, 10 \% \mathrm{M}, 1 \% \mathrm{M}, 1 \% \mathrm{FP}, 10 \% \mathrm{FP}, 50 \% \mathrm{FP}, 90 \% \mathrm{FP}, 100 \% \mathrm{FP}$ and carbon concentrations between surface and core

$$
\begin{aligned}
& \left(\mathrm{C} \in\left[\mathrm{C}_{\mathrm{m}} ; \frac{\mathrm{C}_{\mathrm{m}}+\mathrm{C}_{\mathrm{ef}}}{2} ; \mathrm{C}_{\mathrm{ef}} ; \frac{\mathrm{C}_{\mathrm{ef}}+\mathrm{C}_{\mathrm{S}}}{2} ; \mathrm{C}_{\mathrm{S}}\right]\right) \\
& V_{C r 700}{ }_{100 \% M}=9.81-\left(4.62 \% \mathrm{C}+0.78 \% \mathrm{Mn}+0.41 \% \mathrm{Ni}+0.80 \% \mathrm{Cr}+0.66 \% \mathrm{Mo}+0.0018 \mathrm{P}_{A}\right) \text {; } \\
& V_{C r 700_{90 \% M}}=8.76-\left(4.04 \% \mathrm{C}+0.86 \% \mathrm{Mn}+0.36 \% \mathrm{Ni}+0.58 \% \mathrm{Cr}+0.97 \% \mathrm{Mo}+0.0010 P_{A}\right) \text {; } \\
& V_{C 700_{50 \% M}}=8.20-\left(3.0 \% \mathrm{C}+0.79 \% M n+0.57 \% \mathrm{Ni}+0.67 \% \mathrm{Cr}+0.94 \% \mathrm{Mo}+0.0012 P_{A}\right) \\
& V_{C r 700}{ }_{10 \% M}=9.80-(3.9 \% \mathrm{C}-0.54 \% \mathrm{Mn}+2.45 \sqrt{\% \mathrm{Mn}}+0.46 \% \mathrm{Ni}+0.50 \% \mathrm{Cr}+ \\
& \left.1.16 \% \mathrm{Mo}+0.0020 P_{A}\right) \text {; } \\
& V_{C r 700_{1 \% M}}=8.56-\left(1.5 \% \mathrm{C}+1.84 \% \mathrm{C}+0.78 \% \mathrm{Ni}+1.24 \% \mathrm{Cr}+1.46 \% \mathrm{Mo}+0.0020 \mathrm{P}_{A}\right) \\
& V_{C r 700_{1 \% F P}}=10.55-\left(4.80 \% \mathrm{C}+0.80 \% \mathrm{Mn}+0.72 \% \mathrm{Ni}+1.07 \% \mathrm{Cr}+1.58 \% \mathrm{Mo}+0.0026 \mathrm{P}_{A}\right) \text {; } \\
& V_{C r 700}=9.06-\left(4.11 \% C+0.90 \% M n+0.60 \% N i+1 \% C r+2 \% M o+0.0013 P_{A}\right) \text {; } \\
& \mathrm{V}_{\mathrm{cr} 700_{50 \% \mathrm{FP}}}=8.04-\left(3.40 \% \mathrm{C}+1.15 \% \mathrm{Mn}+0.96 \% \mathrm{Ni}+1 \% \mathrm{Cr}+2 \% \mathrm{Mo}+0.0007 \mathrm{P}_{\mathrm{A}}\right) \\
& V_{C 700_{90 \% M}}=8.40-\left(2.80 \% \mathrm{C}+1.51 \% \mathrm{C}+1.03 \% \mathrm{Ni}+1.1 \% \mathrm{Cr}+2 \% \mathrm{Mo}+0.0014 \mathrm{P}_{A}\right) \text {; } \\
& \mathrm{V}_{\mathrm{cr} 700_{100 \% \mathrm{FP}}}=8.56-\left(1.5 \% \mathrm{C}+1.84 \% \mathrm{Mn}+0.78 \% \mathrm{Ni}+1.24 \% \mathrm{Cr}+2 \sqrt{\mathrm{Mo}}+0.0020 \mathrm{P}_{\mathrm{A}}\right) \\
& 6^{\circ} \text { Calculates critical cooling speed } \mathrm{v}_{700} \text { and its logarithm } \\
& V_{700}=1 \cdot 8 \cdot 10^{6} \cdot E^{-1,41}\left[{ }^{\circ} \mathrm{C} / h\right] \\
& \lg V_{700} \\
& {\left[\mathrm{Cm} ; \frac{\mathrm{Cm}+\mathrm{Cef}}{2}, \mathrm{Cef}, \frac{\mathrm{Cef}+\mathrm{Cs}}{2}, \mathrm{Cs}\right] \text {; }}
\end{aligned}
$$

The hardnesses of martensite, bainite, ferrite+perlite constituents;

$H V_{M}=902.6 \% C+26.68 \lg V_{700}+121.156$ 
$H V_{B}=185 \% C+330 \% S i+153 \% M n+144 \% C r+65 \% N i+191 \% M o+(89+53 \% C-55 \% S i$ $-22 \% \mathrm{Mn}-20 \% \mathrm{Cr}-10 \% \mathrm{Ni}-33 \% \mathrm{Mo}) \lg V_{700}-323$

$H V_{F P}=\left(1329 \% C^{2}-744 \% C+15 \% C r+4 \% N i+135.4\right) \lg V_{700}+3300 \% C-5343 C^{2}-437 ;$

$10^{\circ}$ Calculates the global hardness, $\mathrm{HV}_{\text {mixture }}$ for different carbon concentrations

$H V_{\text {mixture }}=\% F P . H V_{F P}+\% B \cdot H V_{B}+\% M \cdot H V_{M}$;

$\mathbf{1 1}^{\circ}$ Draw up $\mathrm{HV}_{\text {mix }}=\mathrm{f}(\% \mathrm{C})$;

$12^{\circ}$ For a set value for the effective case depth, $\delta_{\mathrm{ef}}$, determines the carburising depth, $\mathrm{t}_{\mathrm{K}}$, from the relation:

$\mathrm{C}_{\mathrm{ef}}=\mathrm{C}_{0}\left[\frac{0.79 \sqrt{\mathrm{D} \cdot \mathrm{t}_{\mathrm{K}}}-0.24 \delta_{\mathrm{ef}}}{\delta_{\mathrm{ef}}}\right]\left(\mathrm{C}_{\mathrm{S}}-\mathrm{C}_{0}\right)$;

$13^{\circ}$ For different values of the maintaining time at carburising, in the $\left(0 ; t_{K}\right]$, determines the correlation of $\mathrm{C}_{\delta}=\mathrm{f}(\delta)$, for $\delta \in\left(\mathrm{o}, \delta_{\mathrm{ef}}\right]$,

$\mathrm{C}_{\delta}=\mathrm{C}_{0}\left[\frac{0.79 \sqrt{\mathrm{D} \cdot \mathrm{t}_{\mathrm{K}}}-0.24 \delta}{\delta}\right]\left(\mathrm{C}_{\mathrm{S}}-\mathrm{C}_{0}\right)$;

$14^{\circ}$ Calculates $\mathrm{Ms}$, for different carbon percentages, between $\mathrm{C}_{0}$ and $\mathrm{C}_{\mathrm{s}}$ for

$\left[\mathrm{C}_{0} ; \frac{\mathrm{C}_{0}+\mathrm{Cef}}{2}, \mathrm{Cef}, \frac{\mathrm{Cef}+\mathrm{Cs}}{2}, \mathrm{Cs}\right]$

$M_{S}=548--440 \% \mathrm{C}-(14 \% \mathrm{Si}+26 \% \mathrm{Mn}+11 \% \mathrm{Cr}+14 \% \mathrm{Ni}+9 \% \mathrm{Mo})$;

$15^{\circ}$ Calculates the proportion of residual austenite for:

$\left.\mathrm{C}_{0} ; \frac{\mathrm{C}_{0}+\mathrm{Cef}}{2}, \mathrm{Cef}, \frac{\mathrm{Cef}+\mathrm{Cs}}{2}, \mathrm{Cs}\right]$;

$\% A R=100 \exp [-0.011($ Ms - 20)];

$16^{\circ}$ Calculates the hardness variation due to residual austenite for different carbon proportions $\left.\mathrm{C}_{0} ; \frac{\mathrm{C}_{0}+\mathrm{Cef}}{2}, \mathrm{Cef}, \frac{\mathrm{Cef}+\mathrm{Cs}}{2}, \mathrm{Cs}\right]$

$\left[\Delta H V=\frac{\% A R}{0.10+0.015 \% A R}\right]$

$17^{\circ}$ Calculates the corrected value of hardness, $\mathrm{HV}_{\text {corrected }}$

$H V_{\text {corrected }}=H V_{a m}-\Delta H V$;

$1 \mathbf{8}^{\circ}$ Draw up the dependency $\mathrm{HV}_{\text {corrected }}=\mathrm{f}(\% \mathrm{C})$ for the carbon content in limits $\left[\mathrm{C}_{\mathrm{o}}, \mathrm{C}_{\mathrm{s}}\right]$;

$19^{\circ}$ Corroborate the data from stages 13 and 18 and draw up $\operatorname{HV}_{\text {corrected }}=f(\delta)$

\section{STOP}

Fig. 17. Algorithm for a software used for in characterization of the effects of the carburising-quenching cycle applied to case hardening steels. 


\section{References}

[1] Murry, G. (1971). Mem.Scient.Rev.Met, no.12,pp.816-827

[2] Bussmann, A. (1999). Definition des mathem.Modells,CET

[3] Jatczak, C. F. (1971). Determining Hardenability from Composition. Metal Progress, vol.100, no.3, pp.60-65

[4] Wyss, U. (1988) Kohlenstoff und Härteverlauf in der Einsatzhärtungsschicht verschieden legierter Einsatzstähle, Härt.Tech.Mitt., no.43,1

[5] Popescu, N., Cojocaru, M. (2005). Cementarea oțelurilor prin instilarea lichidelor organice. Ed.Fair Partners, pp.115, Bucuresti

[6] Just, E. (1986). Formules de trempabilité. Härt.Tech.Mitt., no.23, pp.85-100

[7] Roempler, D., Weissohn, K. H. (1989). Kohlenstoff und Härteverlauf in der Einsatzhärtungsschicht-Zusatzmodul für Diffusionrechner, AWT-Tagung, Einsatzhärten, Darmstadt

[8] Maynier, Ph., Dollet, J., Bastien, P. (1978). Hardenability Concepts with Applications to Steel, AIME, pp.163-167, 518-545

[9] Carsi, M., de Andrés, M.P. (1990). Prediction of Melt-Hardenability from Composition. Symposium IFHT, Varşovia

[10] Eckstein, H.J. (1987). Technologie der Wärmebehandlung von Stahl. VEB Deutscher Verlag für Grundstoffindustrie,Leipzig 


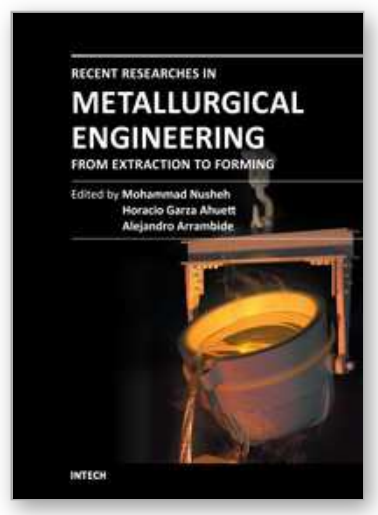

\author{
Recent Researches in Metallurgical Engineering - From Extraction \\ to Forming \\ Edited by Dr Mohammad Nusheh
}

ISBN 978-953-51-0356-1

Hard cover, 186 pages

Publisher InTech

Published online 23, March, 2012

Published in print edition March, 2012

Metallurgical Engineering is the science and technology of producing, processing and giving proper shape to metals and alloys and other Engineering Materials having desired properties through economically viable process. Metallurgical Engineering has played a crucial role in the development of human civilization beginning with bronze-age some 3000 years ago when tools and weapons were mostly produced from the metals and alloys. This science has matured over millennia and still plays crucial role by supplying materials having suitable properties. As the title, "Recent Researches in Metallurgical Engineering, From Extraction to Forming" implies, this text blends new theories with practices covering a broad field that deals with all sorts of metalrelated areas including mineral processing, extractive metallurgy, heat treatment and casting.

\title{
How to reference
}

In order to correctly reference this scholarly work, feel free to copy and paste the following:

Mihai Ovidiu Cojocaru, Niculae Popescu and Leontin Drugă (2012). The Estimation of the Quenching Effects After Carburising Using an Empirical Way Based on Jominy Test Results, Recent Researches in Metallurgical Engineering - From Extraction to Forming, Dr Mohammad Nusheh (Ed.), ISBN: 978-953-51-0356-1, InTech, Available from: http://www.intechopen.com/books/recent-researches-in-metallurgical-engineering-fromextraction-to-forming/the-estimation-of-the-quenching-effects-after-carburising-in-an-empirical-way-using-thejominy-test-

\section{INTECH}

open science | open minds

\section{InTech Europe}

University Campus STeP Ri

Slavka Krautzeka 83/A

51000 Rijeka, Croatia

Phone: +385 (51) 770447

Fax: +385 (51) 686166

www.intechopen.com

\section{InTech China}

Unit 405, Office Block, Hotel Equatorial Shanghai

No.65, Yan An Road (West), Shanghai, 200040, China

中国上海市延安西路65号上海国际贵都大饭店办公楼 405 单元

Phone: +86-21-62489820

Fax: $+86-21-62489821$ 
(C) 2012 The Author(s). Licensee IntechOpen. This is an open access article distributed under the terms of the Creative Commons Attribution 3.0 License, which permits unrestricted use, distribution, and reproduction in any medium, provided the original work is properly cited. 